\title{
Memory of the UK's 2016 EU \\ Referendum: the effects of valence on the long-term measures of a public event
}

Article

Accepted Version

Raw, J., Rorke, A., Ellis, J., Murayama, K. and Sakaki, M. ORCID: https://orcid.org/0000-0003-1993-5765 (2021) Memory of the UK's 2016 EU Referendum: the effects of valence on the long-term measures of a public event. Emotion. ISSN 1931-1516 doi: https://doi.org/10.1037/emo0000788 Available at https://centaur.reading.ac.uk/98838/

It is advisable to refer to the publisher's version if you intend to cite from the work. See Guidance on citing.

To link to this article DOI: http://dx.doi.org/10.1037/emo0000788

Publisher: American Psychological Association

All outputs in CentAUR are protected by Intellectual Property Rights law, including copyright law. Copyright and IPR is retained by the creators or other copyright holders. Terms and conditions for use of this material are defined in the End User Agreement.

www.reading.ac.uk/centaur 
Central Archive at the University of Reading

Reading's research outputs online 
Memory of the UK's 2016 EU Referendum: The effects of valence on the longterm measures of a public event.

Jasmine Raw ${ }^{1}$, Alice Rorke ${ }^{1,}$ Judi Ellis ${ }^{1}$, Kou Murayama $^{1,2}$, \& Michiko Sakaki ${ }^{1,2}$

${ }^{1}$ School of Psychology and Clinical Language Sciences, University of Reading, UK

${ }^{2}$ Hector Research Institute for Educational Science and Psychology, University of Tübingen, Germany

Corresponding authors:

Jasmine Raw: jasmine.raw@ pgr.reading.ac.uk

Michiko Sakaki: michiko.sakaki@uni-tuebingen.de

School of Psychology and Clinical Language Sciences, University of Reading, Reading, RG6 6AL, UK

Acknowledgement: This work was supported by grants from the European Commission (PCIG13-GA-2013-618600), the British Academy (SG140072), and the Japan Society for the Promotion of Science (JP16H05959; JH16H06406; JP16H02053). We would like to thank Samantha Francesca Lapid and Nyasha Dhlamini (University of Reading) for their help with coding the data. 


\begin{abstract}
Emotional public events, relative to non-emotional ones, are typically remembered more accurately, more vividly and with more confidence. However, the majority of previous studies investigating this have focused on negative public events and less is known about positive ones. The current study examined whether positive and negative public events were remembered in a similar manner by assessing individuals' memory for the time when they learned the results of the UK's 2016 Referendum on its European Union (EU) membership. Participants included UK participants who voted to 'leave' the EU in the referendum and found the event highly positive, UK participants who voted to 'remain' in the EU and found the event highly negative, and US participants who did not vote and found the event neutral. Data from a total of 851 participants were assessed at four time points over the course of 16 months. Growth curve modelling showed that differences in memory between participants in the Remain group (who reported the highest levels of negative emotion) and those in the Leave group (who reported the highest levels of positive emotion) emerged over time. Specifically, Remain participants maintained higher levels of memory consistency than Leave participants, while Leave participants maintained higher levels of memory confidence than Remain participants. These results indicate that positive and negative public events are remembered differently, such that negative valence enhances memory accuracy, while positive valence results in overconfidence.
\end{abstract}

Keywords: Emotion and memory; Rehearsal; Personal importance; Memory consolidation; Autobiographical memory; Episodic memory 


\section{Introduction}

Emotional items and events are typically remembered better than non-emotional items and events (for reviews see LaBar \& Cabeza, 2006; Talmi, 2013) and are often preserved in memory for longer, sometimes spanning several years (Dolcos et al., 2005; Levine \& Edelstein, 2009). In lab-based settings, this emotion advantage is evident across a range of different stimuli; including words (Dewhurst \& Parry, 2000; LaBar \& Phelps, 1998), pictures (Dolcos et al., 2004; Dolcos \& Cabeza, 2002; Nashiro et al., 2012; Ochsner, 2000; Sakaki et al., 2019) and film clips (Cahill et al., 1996). Emotional stimuli are also often remembered more vividly and with more confidence than neutral stimuli (Cooper et al., 2019; Sharot et al., 2004, 2007; Todd et al., 2012).

Such emotion-induced memory enhancement also extends to real-life autobiographical memories (Talarico et al., 2004). One extreme example of such memories are flashbulb memories that are typically formed following a surprising and highly emotional public event, such as the 9/11 terrorist attack (Curci \& Luminet, 2006; Hirst et al., 2009; Kvavilashvili et al., 2009) or the deaths of well-known figures (R. Brown \& Kulik, 1977; Day \& Ross, 2014; Hornstein et al., 2003). Despite the wealth of research on emotion and memory, however, it has been not clearly understood how similarly positive and negative public events are remembered over time. In the current paper, we investigated whether a public event that is interpreted as either positive or negative is similarly remembered over time by assessing individuals' memory for the United Kingdom (UK)'s 2016 Referendum on their European Union (EU) membership.

Previous studies on emotion and memory often focused on the effects of emotional arousal and suggest that highly arousing emotional stimuli are remembered better than neutral stimuli irrespective of emotional valence (LaBar \& Cabeza, 2006; Schümann et al., 2018; Talmi, 2013; Mather \& Sutherland, 2009). However, there is also an increasing 
recognition that positive and negative valence can influence our memory in different ways (for reviews, see Bowen, Kark \& Kensinger, 2018; Kensinger, 2009). For example, negative faces and scenes were recalled better than positive faces and scenes even when they were matched for arousal (Keightley et al., 2011). Negatively valenced items are also recalled more precisely (Spachtholz et al., 2014; Xie \& Zhang, 2017) and with a greater sense of vividness than neutral and positive stimuli (Dewhurst \& Parry, 2000; Ochsner, 2000; Xie \& Zhang, 2016). Recent research has also shown that individuals' abilities to learn associations between pairs are impaired by negative emotion but facilitated by positive emotion (Madan et al., 2012, 2019).

These findings are consistent with several theoretical frameworks, such as the affectas-information framework (Storbeck \& Clore, 2005) and the NEVER (Negative Emotional Valence Enhances Recapitulation) Forget model (Bowen et al., 2018). According to the affect-as-information theory, positive emotion is thought to broaden our scope of attention (Fredrickson \& Branigan, 2005) and encourages reliance on general knowledge and scripts (Storbeck \& Clore, 2005). Consequently, positive emotion helps us concentrate more on the global characteristics of the event, meaning we are more likely to remember the overall theme or gist (Kensinger, 2009; Levine \& Edelstein, 2009). Conversely, when we experience negative emotion, we adopt bottom-up processing (Clore et al., 2001) and engage in more sensory processes (Mickley \& Kensinger, 2008) which enables us to attend to the specific/sensory details of the event. The mental representations of these sensory details are enhanced and are then more likely to be recapitulated at the time of retrieval. This could in turn increase the subjective feelings of vividness in an individual's memory and improve the mnemonic preciseness in the perceptual details associated with negative, rather than positive, memories (Bowen et al., 2018; Bowen \& Kensinger, 2017). 
However, it is not clearly understood whether and how these laboratory findings extend to memories for real-life events. In fact, positive autobiographical experiences are frequently rated as richer (Ford et al., 2012) and are recalled more frequently (Bohn \& Berntsen, 2007; D’Argembeau et al., 2003; Walker et al., 2003) and with greater sensorial detail compared to negative ones (Destun \& Kuiper, 1999; A. Schaefer \& Philippot, 2005). These findings are contrary to the findings of lab-based research and suggest the idea that positive emotion may offer a mnemonic advantage over negative emotion. One possible explanation about these differences is that lab-based studies significantly differ in their methodological approaches to autobiographical memory studies. Notably, autobiographical memory studies often focus on what participants remember using a single memory assessment, without having an objective measure about what actually happened. This makes it difficult to understand how positive and negative valence affects the accuracy or consistency of autobiographical memories.

To address this issue, other studies obtained a baseline measure about what has happened to participants (Bohannon, 1988; Hirst et al., 2009; Kraha et al., 2014; Kvavilashvili et al., 2009; Talarico \& Moore, 2012). One notable example is research on flashbulb memories. Flashbulb memories are memories about the personal circumstances in which one first learns about a surprising and emotional public event (Conway et al., 1994; Hirst et al., 2018), such as the deaths of public figures (Day \& Ross, 2014; Demiray \& Freund, 2015; Tinti et al., 2014), political events (e.g., the fall of the Berlin Wall; Bohn \& Berntsen, 2007), the resignations of Prime Ministers (e.g. Conway et al., 1994; Stone et al., 2015), the Fukushima nuclear disaster (Talarico et al., 2019), the inauguration of President Obama (Koppel et al., 2013) and sporting events (Breslin \& Safer, 2011; Kopietz \& Echterhoff, 2014; Merck et al., 2020; Talarico \& Moore, 2012; Tinti et al., 2014). In research on flashbulb memories, researchers typically assess how participants learnt of an emotional 
public event shortly after it occurred, followed by a subsequent assessment about the same memory a few months or years later. This method allows researchers to estimate the accuracy of participants' memories based on how consistent their memories are across the multiple assessments (i.e., if their descriptions substantially change between the first vs. subsequent assessments, their memories are less likely to be accurate).

Using such methods, previous research has found that while flashbulb memories are susceptible to distortion (Schmolck et al., 2000; Talarico \& Rubin, 2003), they are more accurate than memories for ordinary events (Christianson, 1989; Conway et al., 1994; Curci \& Luminet, 2006; Hornstein et al., 2003). Flashbulb memories are also associated with high confidence (Hirst et al., 2009; Talarico \& Rubin, 2007) and high vividness even after a long passage of time (Hirst et al., 2015). These preserved phenomenological features of flashbulb memories are revealed to at least partly depend on emotional responses, such as surprise (R. Brown \& Kulik, 1977; Páez et al., 2018), and emotional intensity (Berntsen \& Thomsen, 2005; Tekcan, 2001), suggesting that emotion has beneficial effects on memory even outside of laboratory settings.

While initial research on flashbulb memories are primarily about negative events, more recent research has suggested that individuals can form flashbulb memories even for positive public events (Berntsen \& Thomsen, 2005; Kopietz \& Echterhoff, 2014; Koppel et al., 2013; Kraha et al., 2014). For example, in one study, researchers assessed memories of the fall of Berlin's wall among German citizens who perceived the event as highly positive, those who perceived it as neutral, and those who perceived it as highly negative (Bohn \& Berntsen, 2007). The results indicated that those who perceived the event as positive experienced a stronger sense of reliving the event during retrieval than those who perceived the event as negative. In another study, older adults were asked to report their memories of their personal circumstances for two events related to their experience of World War II in 
Denmark: 1) the German occupation of Denmark in 1940 and 2) Denmark's liberation in 1945 (Berntsen \& Thomsen, 2005). Memories for the invasion were remembered less clearly than memories for the liberation, suggesting that positive emotion may facilitate the formation of flashbulb memories - even more than negative emotion.

To explain these findings, Berntsen proposed the social identity theory of flashbulb memories (Berntsen, 2009). The theory is based on the notion our self-concept includes social identity which concerns our identifications with the social groups that we perceive ourselves as a member of (Tajfel, 1982). Berntsen expanded this theory and posits that individuals form flashbulb memories following a public event when the event is perceived as relevant to a social group to which they belong. When an event is perceived to strongly affect the day-to-day activities of members of a particular social group, it is more likely to attract interest given its perceived importance (Talarico et al., 2019). Consequently, it can lead to stronger emotional reactions (positive or negative), increased rehearsal, and result in frequent communications within the community, such as television/radio programs of the event or conversations about the event with other members in the group (e.g. Day \& Ross, 2014), all of which can help the long-term maintenance of these memories. In addition, since groups are striving to maintain a positive self-image, personal circumstances when hearing positive events can be maintained better than personal circumstances when hearing negative public events.

In summary, the social identity theory and laboratory studies suggest different predictions about how valence can affect our memories in life. As discussed above, previous laboratory studies suggest that negative emotion can lead to more accurate and more vivid memories than positive emotion (e.g., Bowen et al., 2018). In contrast, research on autobiographical memory and the social identity theory suggests that positive emotion can have stronger effects on our memory than negative emotion (Berntsen, 2009). 
Despite such theoretical predictions, there are still relatively few studies that compare memories after a positive versus a negative public event. In addition, those that do make the comparison still provide mixed evidence for the effects of valence. For example some studies have found that vividness (Berntsen \& Thomsen, 2005; Breslin \& Safer, 2011; Kensinger \& Schacter, 2006b), confidence (Bohn \& Berntsen, 2007; Liu et al., 2012; Talarico \& Moore, 2012) and memory consistency (Liu et al., 2012; Talarico \& Moore, 2012) are similar for both positive and negative events. Meanwhile, there is also evidence that positive and negative emotions are differently associated with these measures. For example, some researchers have found an association between positive emotion and higher levels of confidence (Kensinger \& Schacter, 2006b; Kraha et al., 2014), accuracy and/or clarity (Bohn \& Berntsen, 2007; Breslin \& Safer, 2011; Koppel et al., 2013; Levine \& Bluck, 2004) and vividness (Liu et al., 2012; Talarico \& Moore, 2012), offering support for Berntsen's social identity theory. Meanwhile others have found that positive emotion can actually lead to greater levels of inaccuracy (Bohn \& Berntsen, 2007; Demiray \& Freund, 2015; Kensinger \& Schacter, 2006b; Levine \& Bluck, 2004), which is more consistent with the results found in laboratory-based studies.

Furthermore, across these studies, there are two issues which make the interpretation and comparability between them difficult. Firstly, the events themselves are often two separate events (one representative of each valence) that are arguably different in their qualities (Koppel et al., 2013; Kraha et al., 2014). For example, positive events are often personal ones such as being accepted to college, while the negative events are frequently public events such as natural disasters or tragedies, like the 9/11 terror attack (Kraha et al., 2014; Kraha \& Boals, 2014; Liu et al., 2012). Therefore, it is difficult to know whether the differences in memory measures are due to the valence of the events or due to other confounds (e.g., public events receive more media attention than personal events). 
Secondly, previous studies have relied upon one single follow-up assessment which is often obtained at different intervals across studies. However, having a single memory assessment prevents us from being able to understand how emotional autobiographical memories may manifest over time. Likewise, the duration between the event and the initial assessment may also vary for positive and negative events. For example, previous evidence suggests that short-term assessments yield similar levels of consistency and confidence for positive and negative events (Talarico \& Moore, 2012) while longer intervals lead to better memory accuracy but lower confidence for negative events (Kensinger \& Schacter, 2006b). Therefore, these conflicting findings may simply be due to the differences in the duration between the event and the assessment of memory as opposed to the direct effects of valence.

\section{Current Research}

The current research aims to address these two issues by assessing participants' memory for a single event over four separate surveys in order to reveal the effects of valence on emotional event memories. Secondly, drawing on the large body of research on flashbulb memories, we also aimed to examine how memories for positive and negative public events similarly vs. differently rely upon factors that have been implicated in the formation and the maintenance of flashbulb memories beyond emotional reactions, including levels of rehearsal and personal importance (Conway et al., 1994; Finkenauer et al., 1998; Talarico \& Rubin, 2017).

To achieve these goals, we assessed memory for the same event - the UK's $2016 \mathrm{EU}$ Referendum in which the public voted for the UK to leave the European Union (EU) membership, in (a) UK participants who voted to leave the EU and found the event highly positive (i.e., Leave) and (b) UK participants who voted to remain in the EU and found the event highly negative (i.e., Remain). The referendum result indicated the UK's future intention to end the political and economic partnership with the EU that had been maintained 
since 1975. Thus, it had the potential to affect lives of many individuals who lived in the UK in a range of domains: legislation, the freedom of movement, the UK's trade with other EU countries and so on. Leading up to the official vote, both online- and telephone-polls yielded neck and neck results for both Leave and Remain parties, signaling a high level of uncertainty in the overall outcome (Barnes, 2016). The marginal 'Leave' win with 51.9\% of the votes (The Electoral Commission, 2016) was met with high levels of surprise both amongst the UK public and World-Leaders. Therefore, this political event provided us with an ideal opportunity to investigate peoples' memories for a highly surprising and important event that yielded both a positive and negative outcome depending on peoples' voting choice (i.e. Leave vs Remain). As is the case in other studies of public events (Conway et al., 1994; Curci et al., 2001; Kvavilashvili et al., 2003; Luminet et al., 2004; Tinti et al., 2009), a control group from outside the region/country where the event occurred was also included. In this specific event, US participants did not vote on the issue and were presumed to have more emotionally neutral feelings towards the event; as such, we recruited US residents who did not vote in the referendum as the control group.

Using such a design, we examined the effects of valence on consistency, confidence and vividness for memory for the same event over time. In four separate surveys, at one week and then, three, nine and 16 months after the EU Referendum results, participants answered a number of questions relating to their memory for when they learnt about the EU Referendum results. We focused on the consistency of canonical features of the memories (R. Brown \& Kulik, 1977), including where they were, what time it was, who they were with, how they found out (source of information), what they were doing beforehand, and what they did afterwards. We also assessed subjective memory vividness, subjective memory confidence, positive emotion, negative emotion, and other factors that have been implicated in the formation of flashbulb memories, such as surprise, rehearsal, and personal importance. 
UK participants were able to vote in the referendum; an event that was arguably highly relevant to their social group status as UK participants. They were thus more likely to be invested in the outcome and be directly impacted by the results than US participants were. Therefore, we expected that compared to their US counterparts, the two UK voting groups would be more likely to form memories that have features similar to flashbulb memories (i.e., memories that were more confidently held, more consistent and more vivid) due to their higher levels of long-term personal importance, emotional intensity, surprise and rehearsal. We also expected Remain participants to report higher ratings of negative emotion than Leave participants and US participants because the results of the referendum were not congruent with their voting choice. In contrast, we expected that Leave participants expressed higher ratings of positive emotion than Remain participants and US participants. Given that the previous literature provides mixed results on whether a particular valence is associated with more consistent, more vivid and/or more confidently held memories, we did not have a specific directional hypothesis but examined a) whether Remain and Leave participants demonstrated different levels of memory consistency, vividness and confidence; and b) whether any differences between the two groups changed across time. We also examined whether the effects of voting choice on our memory measures were mediated by any of the factors identified in the literature such as positive emotion, negative emotion, surprise, rehearsal and personal importance.

\section{Methods}

\section{Survey Overview}

The surveys were administered using SurveyGizmo ${ }^{1}$ (https://www.surveygizmo.com). Figure 1 represents the timing of each survey. Survey 1 started on July 01, 2016 - one week after the EU Referendum results were announced on June 24, 2016, and continued for a

\footnotetext{
${ }^{1}$ Now called Alchemer (https://www.alchemer.com/).
} 
period of ten days until the 11 July, 2016. For the second and third surveys (Surveys 2 and 3), we recruited participants for three weeks and for the fourth survey (Survey 4), the duration of recruitment was increased to 3 weeks and 5 days to maximize participant retention. The recruitment dates and duration for each follow-up survey were as follows: Survey 2 was between October 14, 2016 and November 11, 2016, Survey 3 was between April 5, 2017 and April 26, 2017 and Session 4 was between October 13, 2017 and November 8, 2017.

\section{Participants and Recruitment}

Participants were aged between 18 and 87 and resided in either the UK or the US. They were recruited through Prolific (https://www.prolific.co/), other websites such as http://psych.hanover.edu/research/exponnet.html, personal communications, the Undergraduate Research Panel at the University of Reading in the UK and the Older Adult Research Panel at the University of Reading. Participants recruited from Prolific were prescreened so that we could target those (i) with a UK or US nationality, (ii) who resided in the UK or US, (iii) who were born in the UK or US, (iv) who voted in the EU referendum (for UK participants) ${ }^{2}$ and (v) with a study approval rating of $90 \%$ and above which has previously been associated with higher quality data (Peer et al., 2014). Participants recruited from Prolific were paid $£ 1$ after completing each survey and students from the Undergraduate Research Panel received course credit after completing each survey. The remaining participants received an Amazon money voucher ( $£ 1$ per survey), or a check ( $£ 1$ per survey) after completing all follow up surveys. Participants signed an electronic version of the consent form that was given a favorable opinion by the University Research Ethics Committee.

\footnotetext{
${ }^{2}$ This was implemented from Survey 2 onward. While collecting data for Survey 2, we also specifically recruited participants who voted to leave the EU in Prolific in order to recruit a similar number of Leave and Remain participants.
} 
In order to model the change in memory consistency over time, it was important for us to have data from participants who had completed the initial survey and at least two other follow-up surveys. Considering an expected return rate between 55 and $70 \%$ for each survey as is seen in previous longitudinal flashbulb memory studies (Holland \& Kensinger, 2012; Levine \& Bluck, 2004), we aimed to recruit at least 150 participants (per group) in the first survey to achieve the statistical power of .80 to detect the valence effects observed in Kensinger and Schacter (2006) in the final sample. At the end of each survey, participants were asked if they would be happy to be contacted again for a follow-up survey and if so, were asked to provide an email address. For ethical reasons, only those that stated 'yes' to the follow-up invitation were invited back. For the third and fourth survey, we invited all participants who had previously indicated their willingness to be contacted again, even if they had missed a survey in between. For each follow-up study, we also recruited additional participants who had not completed the previous survey to increase our statistical power.

Prior to data analysis, we removed data from participants due to the following exclusion criteria. First, we excluded data from those (i) who did not complete the consent form process correctly $(n=3)$, (ii) who provided answers that were not genuine and did not answer the questions correctly $(n=1$; e.g., entering lengthy paragraphs relating to a completely different topic and (iii) those who could not be tracked due to inaccuracies in their unique identifying code/ Prolific ID from each individual survey wave $(n=16)$. Second, we checked for duplicated answers and found that 36 participants completed one of the surveys more than once; for these participants, we removed their second responses and used their first responses in our analyses. We next identified participants who could not be clearly assigned to a group (e.g., non-UK nationals who resided in the UK but were not eligible to vote; UK nationals who resided in the US); data from these participants $(n=212)$ were also not included in our analysis. In addition, since our longitudinal analysis required participants to 
have more than one survey observation, we could not include data from participants who had completed one survey only $(n=899)$. To ensure reliability of data and to address possible occasions of character misrepresentation (Chandler \& Paolacci, 2017; Shapiro et al., 2013) in the remaining sample, we also excluded data from participants (i) who did not provide consistent answers to questions on demographic and voting questions (e.g. gender, voting choice, voting eligibility and age) across different surveys and (ii) those who never had a UK or US IP address across (Keith et al., 2017) any of the surveys they participated in $(n=29)$.

Participants included in the final analysis for memory vividness and confidence included a total of 851 individuals comprised of 267 Leave (149 females; age range: 18-82; Mage $=42.94, \mathrm{SD}=14.04 ;$ Survey 1: 153, Survey 2: 214, Survey 3:212, Survey 4: 174), 275 Remain (178 females; age range: $18-87 ;$ Mage $=40.10, \mathrm{SD}=16.94 ;$ Survey 1: 190 , Survey 2: 226, Survey 3: 222, Survey 4: 176) and 309 US participants (149 females; age range: 18$77 ;$ Mage $=36.88, \mathrm{SD}=13.65 ;$ Survey 1:217, Survey 2: 238, Survey 3: 228, Survey 4: 163; see Table 1). As memory consistency scores could only be generated if the participant had taken part in the initial survey (see Coding of Autobiographical Memories), analyses on this measure were performed on data from a sub-set of participants who completed the first survey: 153 Leave (90 females; age range: 18-83; Mage = 43.07, $\mathrm{SD}=15.21$; Survey 1: 153, Survey 2: 140, Survey 3: 98, Survey 4: 80), 190 Remain (120 females; age range: 18-87; Mage $=41.94$, SD $=17.69 ;$ Survey 1: 195, Survey 2: 172 , Survey 3: 139 , Survey 4:112) and 217 US participants (91 females; age range: 18-75; Mage $=37.41, \mathrm{SD}=13.79$; Survey 1: 217, Survey 2: 177, Survey 3: 144, Survey 4: 94$)^{3}$.

\footnotetext{
${ }^{3}$ To compare those who completed Survey 1 only vs. those who completed Survey 1 and later surveys, a series of 2 (returning status: Survey 1 only vs. returning participants) x 3 (voting group: Remain, Leave vs. US) ANOVAs were conducted as well as a chi-square test of independence for gender (males vs. females) by returning status (Survey 1 only vs. returning participants). These analyses showed that there were no differences in those who dropped out vs. those who remained on gender, $\chi^{2}(1)=2.74, p=.09$, their initial levels of memory
} 


\section{Surveys}

Each survey began with an electronic information sheet, detailing the purpose and aim of the study along with an electronic consent form. Each returning participant was also sent a unique identifying code that they generated in the previous survey, allowing us to track them over time. Participants were told that the study concerned their memories for the UK's 2016 EU referendum. The main content in each survey was similar across the four surveys (see: https://osf.io/swu5a/). In the current study, we focused on the following questions: a) participants' voting choice, b) their memories of learning the outcome of the EU referendum, and c) potential predictors of the formation and maintenance of flashbulb memories implicated in the literature (see Table 2 for a summary of the questions that are relevant to the results presented in this paper).

Voting choice. Participants were asked to indicate their voting eligibility ("Were you eligible to vote in the 2016 UK's EU referendum?"; Question 9 in Table 2). Those who indicated that they were eligible were further asked to indicate their voting choice ("How did you vote?"; Question 10) with three options: (a) "to leave the EU", (b) "to remain in the EU" or (c) "I was eligible but did not vote".

vividness, $F(1,902)=1.98, p=.16, \eta^{2}=.002$, surprise, $F(1,902)=0.07, p=.79, \eta^{2}=.001$, personal importance, $F(1,902)=1.03, p=.47, \eta^{2}=.001$, or negative emotion, $F(1,902)=$ $1.25, p=.27, \eta^{2}=.001$. However, we found significant main effects of returning status for age, $F(1,902)=14.46, p<.00, \eta^{2}=0.02$, and a significant interaction for level of education, $F(2,894)=6.51, p<.01, \eta^{2}=0.01$. Those who returned to the survey were older $(M=38.77$, $S D=15.45)$ than adults who dropped out $(M=35.45, S D=13.73)$ and among Remain participants, those who dropped out had lower levels of education $(M=4.04, S D=0.93)$ than those who returned $(M=4.42, S D=1.02 ; p<.001)$. In addition, we found a main effect of returning status for initial levels of rehearsal, $F(1,894)=6.24, p=.015, \eta^{2}=0.01$, indicating that returning participants reported higher levels of rehearsal $(M=3.94, S D=1.03)$ compared to those who did not return $(M=3.74, S D=1.12)$. The same was found for initial levels of positive emotion, $F(1,901)=4.01, p=.045, \eta^{2}=0.004$. When examining the number of surveys taken, we found a main effect of group, $F(1,558)=9.58, p<.001, \eta^{2}=0.02$. Posthoc comparisons using Bonferroni's correction found that Remain participants, on average, participated in a greater number of surveys than US participants, $p<.001$. 
Memory properties. We administered six questions to establish consistency of their memories (Questions 2-7 in Table 2) by asking for their circumstances when they found out the results of the referendum. The questions were taken from previous studies on flashbulb memories (e.g. R. Brown \& Kulik, 1977; Hirst et al., 2009) and covered the following aspects: (i) the time: "What time was it when you found out the results?"; (ii) the source of information: "How did you learn the outcome?"; (iii) the location: "Where were you when you found out the results?"; (iv) other people: "Who else was there when you found out?"; (v) activities beforehand: "What were you doing beforehand?"; and (vi) activities afterwards: "What did you do immediately after finding out the results?" For the question about the source of information, participants were asked to select if they had learned the outcome through a) the television, b) the internet, c) friends and family, d) a newspaper, e) the radio or f) other. For the remaining questions, participants were asked to describe their circumstances in one sentence. They were also told that their responses to these questions should be specific. We also assessed subjective vividness of their memory ( "How vividly do you remember the time you became aware of the referendum outcome?"; Question 1) with a 7point Likert scale (1: “not very" - 7: “extremely”). In Survey 2 and subsequent surveys, we also measured their memory confidence ("How confident are you in your overall recollection of when you found out the referendum results?"; Question 8) again with a 7-point Likert scale (1: "not at all" - 7: “extremely").

\section{Potential predictors.}

Positive and negative emotion. Participants were presented with five items (angry, sad, anxious, happy and proud) and asked to indicate how strongly they felt each of these emotions when they thought of the referendum (Questions 11a-11e; all with 7-point Likert scales ranging from 1: "not at all" to 7: "very strongly"). 
Two separate scores were created: one to reflect negative emotion by averaging the three items on negative emotion (angry, sad and anxious; $\alpha=.89$ ) and one to reflect positive emotion by averaging the two items on positive emotion (happy and proud; $r=.91, p<.001$; see S-Table 1 for their correlations at Survey 1).

Surprise. Participants also indicated how strongly they felt surprise when they thought of the referendum (Question 11f; using the same 7-point Likert scale as the one used for other emotional states). Although surprise is considered to be an emotional reaction, it is often considered to be a separate predictor to emotional intensity (Bohn \& Berntsen, 2007; Conway et al., 1994; Er, 2003; Finkenauer et al., 1998). In addition, surprise is often emotionally neutral (Fontaine et al., 2007). Therefore, ratings of surprise were used as an independent measure from the other items on emotion.

Personal importance. Levels of personal importance were assessed using a single question ("How important are the referendum results to you?") with a 7-point Likert scale ranging from 1 ("not important") to 7 ("extremely important"; Table 2, Question 12). The question was based on similar items used in previous studies on memories for public events (Holland \& Kensinger, 2012; Kensinger et al., 2005).

Rehearsal. We also assessed levels of rehearsal. In Survey 1, we used four questions (Questions 13-16). Three of them were obtained from previous studies (e.g. Bohn \& Berntsen, 2007; Conway et al., 1994; Kensinger \& Schacter, 2006a) and asked participants to indicate: 1) how much they followed the media coverage of the referendum result in the past week, 2) how much they thought about the referendum since finding out the results, and 3) how much they talked about the referendum with their friends/family and colleagues. We also expected that many participants relied on the internet to gather information (Hirst et al., 2010; Luminet et al., 2004; E. G. Schaefer et al., 2011) and therefore added one more question: how much they spent on the internet reading the latest news about the referendum 
in the past week. For all questions, participants were asked to indicate the most appropriate option on a scale ranging from 1 ("rarely or none of the time or less than 1 day") to 5 (“daily”). In Surveys 2-4, we used similar questions (Questions 17-19) but changed them to assess how much participants had engaged in each activity since the previous survey. We also used a 7-point Likert scales (1: "Very little" - 7: "A great deal") in these follow up assessments.

A current rehearsal score was calculated for Surveys 2, 3 and 4 by averaging the four questions (Questions a-d for 17-19 respectively; $\alpha$ values >.92). We also obtained the average level of rehearsal at Survey 1 by averaging Questions 13-16 $(\alpha=.92)$; since these questions were answered using a different scale (a 5-point scale) than rehearsal-related questions in the rest of the surveys (a 7-point scale), we did not compare levels of rehearsal at Survey 1 versus those at the follow-up surveys.

\section{Coding of Autobiographical Memories}

In order to assess memory consistency over time, the participants' responses to the six main questions (Questions 2-7) from each survey were coded using an adapted version of the Hirst et al. (2009) coding scheme (see Supplementary Materials for further details). This allowed us to create a consistency score for each of the six questions by comparing the coding values in Survey 1 with coding values in Surveys 2, 3 and 4 separately, using the Survey 1 coding value as the baseline measure. Unlike other coding schemes that allow for memories to be considered consistent with varying levels of specificity (e.g. Neisser \& Harsch, 1992), the one developed by Hirst and colleagues uses a two-point classification scheme in which responses are classified as either inconsistent or consistent. For example, if the coding values in Surveys 2, 3 and 4 were the same as Survey 1, the response was given a " 1 " to reflect consistency. If the coding values differed to Survey 1 , then a " 0 " was given to reflect inconsistency. Our final memory consistency score was the averaged overall 
consistency of the six questions ranging from 0 to 1 . The coding was done by several coders who were blind to the survey time and the group the participant belonged to. For each question, a subset (5\%) of the responses was coded by two coders to assess interrater reliability. The percentage agreement between coders was high (>82\%); see Supplemental Materials for results when we used a coding approach similar to the one used in Neisser and Harsch (1992).

\section{Coding of Changes in Memory Content over Time}

To determine whether a positive event was associated with a greater tendency to repeat inconsistent memories than a negative event was and to examine how incorrectly remembered memories change over time, we undertook a second round of coding to assess the consistency between inter-survey responses (i.e., comparing Survey 2 with Survey 3 and Survey 4 and comparing Survey 3 with Survey 4). As done in Hirst et al. (2009), this allowed us to examine whether incorrect memories were repeated, corrected or changed in the subsequent survey. For each question, a subset (10\%) of the responses was coded by two coders to assess interrater reliability. The percentage agreement between coders was high $(>88 \%)$

\section{Data Analysis}

Effects of residency and voting choice on memory properties. One of our primary analyses concerned the effects of voting choice (Leave vs Remain) and residency (UK vs US) on memory consistency, memory vividness and memory confidence. A series of analyses using structural equation modelling (SEM) were carried out in RStudio (v. 1.3.1093) using the lavaan (v. 0.6-7) package (Rosseel, 2012). Specifically, we specified growth curve modelling with SEM (Duncan et al., 2006). This model allowed us to estimate whether voting groups have any short- (initial levels that are reflected by the intercept) and long-term effects (the growth over time that are reflected by the slope) on our dependent variables. Memory 
consistency, confidence and vividness were treated as the dependent variables and each was modelled separately. Orthogonal contrast coding was used to create two group variables; the first was used to compare US participants with UK participants (Leave participants $=-1$, Remain participants $=-1$, and US participants $=2$; referred to as $U K v S U S$ in the model) and the second was used to compare Remain with Leave (Remain participants $=1$, Leave participants $=-1$ and US participants $=0$; referred to as Leave $v$ s Remain in the model). Each model was estimated using maximum likelihood estimations. In addition, a Comparative Fit Measure (CFI), the Robust Tucker-Lewis Index (TLI) and Root Mean Square Error of Approximation (RMSEA) were used to compare the fit of the model. In order to determine a good statistical fit, we accepted models that had CFI and TLI values >.90 (Kline, 2016) and RMSEA values <.08 (Browne \& Cudeck, 1993).

\section{Effects of residency and voting choice on emotional experience and other}

potential predictors of memory measures. To examine how residency and voting choice affected positive emotion, negative emotion and other potential predictors implicated in the formation of flashbulb memories, such as surprise, rehearsal, and personal importance, another series of growth curve modelling were carried out in RStudio, again using the lavaan package. The dependent variables were participants' ratings of the intensity of negative emotion, positive emotion, surprise, rehearsal, and importance, each of which was modelled separately. As in the previous analysis, effect coding was used to create two group variables; 'UK vs US' and 'Leave vs Remain'. This analysis allowed us to assess whether the initial ratings of negative emotion, positive emotion, surprise, rehearsal and personal importance differed across residency and voting group; and whether these variables changed over time in a similar manner across the three groups of participants.

Mediation analysis. In order to understand whether levels of the potential predictors (e.g., surprise, personal importance, negative emotion, positive emotion and rehearsal) 
mediate the effects of residency and voting group on memory consistency, confidence and vividness, we ran three separate mediation analyses. Memory consistency, confidence and vividness were each treated as the dependent variable in these three separate models. Across all three models, the independent variables were residency and voting group and the mediation variables were Survey 1 measures of negative emotion, positive emotion, surprise, personal importance and rehearsal.

\section{Results}

Table 1 describes the demographic characteristics of participants included in our analyses. Table 3 describes means and standard deviations for our main variables for each time point. As described in the Supplemental Materials, our three groups of participants differed on measures of age, gender and education. However, controlling for these variables did not change most of our key results concerning the differences across the two voting groups ${ }^{4}$. Therefore, we report results from analyses without controlling for age, gender and education (see S-Tables 2-3 for results when we controlled these additional variables).

The section is divided into four subsections. In the first section, we present results concerning our first hypothesis that Leave participants should experience more positive

\footnotetext{
${ }^{4}$ There are two exceptions: a) the effects of residency on the slope of memory consistency and b) the initial levels of memory vividness. However, for both of these separate analyses, the results were largely similar irrespective of whether we controlled for the effects of age, gender and education. More specifically, when we did not control for age, gender and education, we found a significant difference in the slope of memory consistency between US and UK participants, which was no longer significant when we controlled for age, gender and education. However, subsequent mediation analyses confirmed a significant difference between UK vs. US participants in the slope for memory consistency irrespective of whether we controlled the effects of age, gender and education. Likewise, when we did not control for age, gender, and education, we found a significant difference in the initial memory vividness between Leave and Remain participants. This effect was no longer significant after controlling for age, gender and education. Nevertheless, subsequent mediation analyses provided a similar picture irrespective of whether we controlled for age, education and gender. Specifically, the analysis revealed that Remain vs. Leave participants were statistically different in their initial memory vividness due to group differences in importance, positive emotion and rehearsal.
} 
emotions and Remain participants should experience more negative emotions towards the EU referendum. In the second section, we describe the effects of the three groups on our three memory measures (i.e., consistency, vividness and confidence). In the third section, we describe results concerning whether the three groups differently affect potential predictors of flashbulb memories (surprise, personal importance, and rehearsal). Lastly, we present results from the mediation analyses, where we examined whether any of these predictors as well as our emotion measures mediate the group effects on memory measures.

\section{Effects of Residency and Voting Choice on Emotional Experiences}

We expected Remain participants to experience more negative emotions than Leave and US participants. Likewise, we expected that Leave participants would experience more positive emotion than Remain participants and US participants. To test these predictions, levels of current negative and positive emotion were separately analyzed using growth curve modelling. Growth curve modelling was performed with levels of negative or positive emotion as the dependent variable and residency (2: US, -1: Remain, -1: Leave) and voting choice (1: Remain vs. -1: Leave) as predictors of growth parameters. The analyses revealed that US participants, compared to UK participants, had lower initial levels of both negative, $\beta=-.37, t=-10.64, p=<.001$, and positive emotion $\beta=-.37, t=-10.35, p<.001$, compared to UK participants (see Tables 3 - 4). US participants also had a steeper decline in negative emotion, $\beta=-.02, t=-2.46, p=.014$, while they had a similar decline in positive emotion to UK participants $(p=.78)$. Thus, consistent with our prediction, our results suggest that US participants experienced more neutral emotion towards the event than UK participants.

In addition, within our UK participants, Remain participants had higher initial levels of negative emotion, $\beta=1.53, t=25.94, p<.001$, but lower initial levels of positive emotion, $\beta=-1.77, t=-28.26, p<.001$, compared to Leave participants. Thus, while UK participants initially had stronger negative and positive emotional responses than US participants did, 
negative emotional responses were driven by Remain participants, while positive emotional responses were driven by Leave participants. We also found that Remain participants showed a steeper decline in their negative emotion than Leave participants, $\beta=-.03, t=-2.73, p=$ .006 , though there was no statistically significant difference in the change of positive emotions over time between Remain and Leave participants, $p=.06$. Nevertheless, Remain participants still reported significantly stronger negative emotion than Leave participants at the last time point (Survey 4), $t(393.41)=-19.01, p<.001, d=-1.80,95 \%$ CI $[-2.29,-1.86]$. Likewise, Leave participants still reported significantly stronger positive emotion than Remain participants at the last time point, $t(387.13)=-11.73, p<.001, d=2.20,95 \%$ CI $[-$ $1.61,-1.15]$. Taken together, these results support our expectation that Remain participants experienced more negative emotions about the event throughout the four surveys while Leave participants experienced more positive emotions. Thus, our two UK voting groups interpreted the event differently in terms of its valence.

\section{Effects of Residency and Voting Choice on Memory}

Next, we specified growth curve modelling with SEM to address our main research question: whether three groups of participants showed differences in measures of memory consistency, confidence and vividness over time.

Memory consistency. The analysis on consistency revealed that UK participants had a higher memory consistency score for Survey $2, \beta=-.05, t=-6.79, p<.001$, but a steeper decline when compared to US participants, $\beta=.003, t=2.03 p=.04$ (Figure 2). Despite their steeper decline in memory consistency, even at Survey 4, UK participants showed more consistent memories than US participants, $t(572)=-10.03, p<.001, d=-.58,95 \%$ CI $[-0.36$, -0.24] (Figure 3A), supporting our prediction that UK participants formed more consistent memories for this political event than US participants. 
In addition, while participants in the Leave vs. Remain group were not significantly different in their initial memory consistency level at Survey $2(p=.37)$, the two voting groups significantly differed in the slope; in other words, Leave participants, relative to Remain participants, exhibited a quicker rate of decline in memory consistency, $\beta=.01, t=$ 2.36, $p=.02$ (see Table 5A). To follow up this interaction, we computed simple slopes for each group separately and found that the difference was being driven by a significant decline in memory consistency over time for Leave participants, simple slope $=-.01, p=.002$, but not for Remain participants, simple slope $=-.0001, p=.89$. Therefore, despite similar initial levels of memory consistency, Remain participants (who considered the event to be highly negative) maintained more consistent memories about the referendum over time compared to Leave participants (who considered the event to be highly positive).

Memory confidence. A similar analysis on memory confidence (Table 5B) revealed that initial confidence levels at Survey 2 (which is reflected by the intercepts) were higher for UK participants compared to US participants, $\beta=-.48, t=-11.03, p<.001$ (Figure 3B). While there were no significant differences between the US and UK participants in their slopes $(p=.92)$, these results also support our prediction that UK participants tend to have stronger confidence over their memory of the time they found the results of the referendum than do US participants.

In addition, we found significant effects of voting choice on the slope, which was in the opposite direction to the memory consistency findings, $\beta=-.03, t=-2.14, p=.03$. More specifically, Remain participants exhibited a quicker rate of decline in memory confidence compared to Leave participants. In contrast, the two voting groups were not significantly different in the initial levels of confidence $(p=.058)$. We next computed simple slopes for Leave and Remain participants separately. This simple slope analysis showed that while both Leave and Remain participants showed significant negative slopes, the decline was more 
pronounced for Remain participants, Leave simple slope $=-.06, p=.008$; Remain simple slope $=-.12, p<.001$. These results show that while initial levels of recollection confidence were similar across Remain participants (who reported feeling highly negative after the event) and Leave participants (who reported feeling positive), Leave participants tended to maintain higher levels of confidence over time.

Memory vividness. A similar analysis on memory vividness (Table 5C) revealed that UK participants, compared to US participants, had higher intercepts for their memory vividness, $\beta=-.51, t=-13.10, p<.001$, with a smaller decline over time (Figure $3 \mathrm{C}$ ), $\beta=-$ $.04, t=-4.39, p<.001$. As in memory consistency and memory confidence, these results support our prediction that UK participants were more likely to have vivid memories for this event than US participants were.

We also found that Remain participants yielded a higher intercept for memory vividness compared to Leave participants, $\beta=.10, t=2.22, p=.027$, but had a similar level of decline over time $(p=.88)$. Thus, Remain participants initially had more vivid memories than Leave participants. However, this effect was no longer significant when controlling for age, levels of education and gender (see S-Table 2).

\section{Effects of Residency and Voting Choice on Changes in Inconsistent Memories over}

\section{Time}

Results reported so far suggest that Remain participants tended to maintain more consistent memories, while Leave participants tended to maintain stronger confidence about their memories despite their less consistent memories (relative to Remain participants). However, these analyses do not tell us changes in the content of inconsistent/incorrect memories over time. Specifically, among participants who had reported an inaccurate memory at Survey 2, some of them reported their inaccurate memory again at Survey 3 ("repeated"), whereas others corrected their errors and reported an accurate memory at 
Survey 3 (“corrected"). If negative emotion, experienced by Remain participants, is associated with more accurate memory, Remain participants may show a greater tendency to correct inconsistent memories than Leave participants. To test these issues, next, we examined whether residency and voting choice affects the changes that occurred in inconsistent/inaccurate memories over time.

As done in previous studies (Hirst et al., 2009, 2015), firstly, we focused on inconsistent memories in Survey 2 and then calculated the proportion of memories that were then either corrected, repeated or changed to other errors (if the memory was neither corrected nor repeated) in Survey 3 (see Table 6). Proportion scores for corrected, repeated and changed memories were then calculated by dividing the sum of each memory type by the total number of incorrect memories. We then repeated the process but this time, concentrated on inconsistent memories in Survey 3 and calculated the proportion of memories that were then corrected, repeated or changed in Survey 4.

Two separate 3 (Group: Remain vs Leave vs US) X 3 (Memory Type: Repeated vs Corrected vs Changed) Mixed Measures ANOVAs were carried out on these proportion measures to examine how the three groups differed in correcting or repeating their errors. The first ANOVA was carried out on participants who had at least one inconsistent memory in Survey 2 and then later took part in Survey 3, comprising of 86 Leave participants (47 females; age range: $18-82$; Mage $=44.36, \mathrm{SD}=15.72), 109$ Remain participants $(71$ females; age range: $18-83 ;$ Mage $=42.16, \mathrm{SD}=17.75)$ and 116 US participants $(51$ females; age range: $18-70 ;$ Mage $=38.12, \mathrm{SD}=13.74)$. This ANOVA revealed a significant main effect of memory type, $F(2,616)=6.71, p=.001, \eta^{2} \mathrm{G}=2.13$, without a significant interaction between group and memory type $(p=.97)$. Post-hoc analysis using a Bonferroni correction revealed that across all participants, incorrect memories in Survey 2 were more likely to be repeated $(M=.41, \mathrm{SD}=.37)$ than corrected $(M=.30, \mathrm{SD}=.35, p<.01)$, or changed $(M=$ 
$.30, \mathrm{SD}=.34, p<.01)$, in Survey 3 . There was no significant difference between changed and corrected memories, $p=1$.

The second ANOVA was carried out on participants who had at least one inconsistent memory in Survey 3 and then later took part in Survey 4, including 60 Leave participants (35 females; age range: $18-82 ;$ Mage $=45.90, \mathrm{SD}=15.74), 91$ Remain participants $(57$ females; age range: $19-84 ;$ Mage $=44.74, \mathrm{SD}=18.55)$ and 73 US participants $(35$ females; age range: 19-70; Mage $=39.51, \mathrm{SD}=13.66$ ). Like the previous ANOVA, there was a main effect of memory type, $F(2,442)=7.24, p<.001, \eta^{2} \mathrm{G}=3.17$, without a significant interaction $(p$ =.66). Post-hoc analysis using a Bonferroni correction revealed that once again, there was a greater tendency for participants to repeat $(M=.42, \mathrm{SD}=.39)$ incorrect memories from Survey 3 in Survey 4 than they were to correct them $(M=.30, \mathrm{SD}=.32, p=.004)$, or change them $(M=.28, \mathrm{SD}=.35, p=.005)$.

Taken together, these findings suggest that incorrect memories were more likely to be repeated over time than they were to be corrected irrespective of voting choice or residency. Thus, while Remain participants tended to maintain more accurate memories over time than the other two groups, once participants formed inaccurate memories, they tended to simply maintain the inaccurate memories in a stable manner across all groups.

\section{Effects of Residency and Voting Choices on Predictive Factors}

The second goal of our study was to examine whether the group differences observed in our memory measures were associated with any of the predictive factors implicated in the formation and maintenance of flashbulb memories (Breslin \& Safer, 2011; Day \& Ross, 2014; Koppel et al., 2013; Talarico \& Moore, 2012; Talarico \& Rubin, 2008). Before doing so, we first tested whether the three groups of participants showed any differences in these predictive factors by separately running a series of growth curve modelling for levels of surprise, personal importance, and rehearsal (Table $7 \mathrm{~A}, \mathrm{~B}$ and $\mathrm{C}$ respectively). 
The results show that UK participants, compared with US participants, had higher intercepts for surprise, $\beta=-.14, t=-3.10, p=.002$, personal importance, $\beta=-.80, t=-23.69, p<.001$, and rehearsal, $\beta=-.67, t=-16.70, p<.001$. Thus, in general, relative to our US participants, our UK participants considered the referendum outcome as more surprising and more personally important, while engaging in more rehearsal. Furthermore, when comparing Leave and Remain participants, we found that Remain participants had higher intercepts for personal importance, $\beta=.16, t=3.37, p<.001$, and rehearsal $\beta=.19, t=2.58, p=.01$, than Leave participants did. However, there was no difference between the two UK groups for the intercept of surprise $(p=.46)$. Thus, while both Leave and Remain participants were as equally as surprised by the EU referendum results, our Remain participants initially considered the EU referendum results to be more personally important and engaged in more rehearsal than our Leave participants did. We also found a significant rate of change for US participants when compared with UK participants on levels of surprise, $\beta=-.02, t=-2.57, p$ $=.01$, and importance, $\beta=-.02, t=-2.45, p=.014$, but not for rehearsal $(p=.67)$. These results indicate that US participants, compared to UK participants, showed steeper levels of decline in ratings of surprise and importance but similar levels of decline for rehearsal. We did not find any significant rates of change between Remain and Leave participants on levels of surprise, importance or rehearsal.

\section{Effects of Predictive Factors on Memory: Mediation Analysis}

To address whether positive and negative emotion and any of other predictive factors such as surprise, personal importance and rehearsal are associated with different patterns in memory consistency across Leave vs. Remain participants, we ran a mediation analysis on memory consistency. The mediation effects were tested using the delta method within the lavaan package. We found that rehearsal in Survey 1 mediated the relationship between voting group and the changes in memory consistency over time, $\beta=0.002, t=2.20, p=.028$. 
Specifically, our Remain participants reported greater levels of rehearsal, $\beta=.35, t=6.54, p$ $<.001$, and greater levels of rehearsal in turn led to a smaller decline in memory consistency over time (see Table 8A; Figure 4), $\beta=.01, t=2.31, p=.02$. These results indicate that Remain participants maintained memory consistency better than Leave participants over time because they had higher levels of initial rehearsal. We also found that positive emotion in Survey 1 mediated the relationship between voting choice and initial memory consistency, $\beta$ $=0.03, t=2.36, p=.018$. In other words, Leave participants had higher levels of positive emotion at Survey $1, \beta=-1.74, t=-21.73, p<.001$, which led to less consistent memories in Survey $2, \beta=-0.02, t=-2.38, p=.02$. None of the other predictive factors showed significant effects on the slope or intercept.

Two separate mediation models, one for the growth curve of memory confidence (see Table 8B; Figure 5) and another for that of memory vividness (see Table 8C; Figure 6), were also carried out to test the potential mediating effects of the predictive factors on the relationship between voting group and vividness and voting group and confidence. Both models identified personal importance and rehearsal as significant mediators for the effects of residency on the intercepts, $\beta=-0.19, t=-3.79, p<.001$ and $\beta=-0.12, t=-3.47, p=.001$, for memory confidence and $\beta=-0.15, t=-3.44, p=.001$ and $\beta=-0.16, t=-6.79, p<.001$, for memory vividness. More specifically, compared with US participants, UK participants engaged in more rehearsal (memory confidence, $\beta=-.44, t=-15.23, p<.001$; memory vividness, $\beta=-.44, t=-15.67, p<.001$ ), and reported higher levels of importance (memory confidence, $\beta=-.77, t=-18.63, p<.001$; memory vividness, $\beta=-.77, t=-18.70, p<.001)$. Higher levels of rehearsal and importance in turn, predicted higher levels of the intercepts both for memory confidence (rehearsal, $\beta=.28, t=3.53, p=<.001$; importance, $\beta=.25, t=$ $3.86, p<.001$ ) and memory vividness (rehearsal, $\beta=.37, t=7.63, p<.001$; importance, $\beta=$ $.19, t=3.55, p<.001)$. These results suggest that higher initial levels of memory confidence 
and vividness among UK participants may be driven by higher levels of perceived importance and stronger engagement in rehearsal.

In addition, we found that the effects of voting choice on the intercept of memory vividness were mediated by three competing effects: a) importance, b) positive emotion, and c) rehearsal. Specifically, relative to Leave participants, Remain participants reported higher levels of importance, $\beta=0.28, t=4.68, p<.001$, and higher levels of rehearsal, $\beta=.34, t=$ $6.33 p<.001$, both of which in turn predicted higher levels of the intercept for memory vividness (rehearsal, $\beta=.37, t=7.63, p=<.001$; importance, $\beta=.19, t=3.55, p<.001$ ). At the same time, Leave participants (relative to Remain participants) reported higher levels of positive emotion, $\beta=-1.76, t=-22.13, p<.001$, which resulted in higher levels of the intercept for memory vividness, $\beta=.09, t=2.11, p=.035$. Thus, while our Leave participants showed lower levels of initial memory vividness than Remain participants in our previous analysis (Table 5), this additional analysis suggests that positive emotion experienced by Leave participants did not impair memory vividness; Instead, positive emotion facilitated memory vividness. Our results further indicate that less vivid memories among Leave participants, relative to Remain participants, are driven by the effects of rehearsal and importance.

The models also tested the mediation effects on the slopes of memory confidence and memory vividness but none of the predictive factors were found to be significant mediators on the slope for memory confidence. For memory vividness, personal importance at Survey 1 significantly affected the slope, $\beta=-.03, t=-2.20, p=.03$, suggesting that personal importance may mediate the effects of voting choice on changes in memory vividness. However, this mediation effect was not significant, $\beta=-0.01, t=-1.94, p=.052$.

\section{Discussion}


Decades of research has shown that emotion has facilitative effects on memory (Kensinger, 2009; LaBar \& Cabeza, 2006; Mather \& Sutherland, 2009; Talmi, 2013). However, previous research does not provide a clear pattern with regards to the effects of valence. Specifically, research in laboratory settings often demonstrates that negative valence leads to mnemonic advantages over positive valence (Dewhurst \& Parry, 2000; Ochsner, 2000), whereas research on autobiographical memories suggests that positive events are remembered better than negative ones (D'Argembeau et al., 2003; Ford et al., 2012; A. Schaefer \& Philippot, 2005; Walker et al., 2003). Research on memories for emotional public events and flashbulb memories also provides mixed evidence on the effects of valence on memory consistency and confidence (Talarico \& Rubin, 2017), possibly due to the lack of comparability across surveys in terms of the number of follow-up surveys, the duration between the event and memory assessment and the types of events that are used.

To address these issues within the literature, in the current study, we examined peoples' memory for the UK's 2016 EU Referendum results. Over four surveys, spanning 16 months, we tested whether memories for the same event differed in the short and long-term measures of memory consistency, vividness and confidence across those who perceived the event to be positive (those who voted to leave the EU) and those who perceived the event to be negative (those who voted to remain in the EU), and US participants who served as controls. Thus, the current study has advantages in the sense that the same event was used for each valence thereby controlling for potential differences in the characteristics of the event.

Consistent with our hypothesis, the two UK groups, compared to their US counterparts, reported higher levels of personal importance, higher engagement in rehearsal (as assessed by thinking, attention to the media and the Internet and through conversations), stronger feelings of surprise, and stronger emotional reactions. The UK participants, relative to the US participants, also displayed higher levels of memory consistency, confidence, and 
vividness, both initially and over time. These findings are consistent with the literature and suggest that flashbulb memories are typically formed for more surprising, emotional and personally important events (R. Brown \& Kulik, 1977; Conway et al., 1994).

According to Berntsen's social identity theory (Berntsen, 2009), when a public event is relevant and important to a particular social group, it can elicit emotional reactions and help sustain rehearsal among its members. This could explain why we found lower levels of memory vividness, confidence and consistency among the US participants because it is unlikely that their social identity, as US participants, was relevant to the UK's EU referendum results. Our findings lend support to previous studies that have found evidence for similar group-level effects (e.g. Berntsen \& Thomsen, 2005; R. Brown \& Kulik, 1977; Conway et al., 1994; Curci et al., 2001; Er, 2003; Kvavilashvili et al., 2003) and suggest that when facing an emotional, important and surprising public event, individuals from a social group for which the event was relevant, were more likely to form consistent and vivid memories that were recalled with greater confidence.

In addition to the difference between UK vs. US participants, we also found that the two UK groups showed different reactions to the event; while Remain participants were just as surprised as Leave participants were, Remain participants reported stronger negative emotion and weaker positive emotion as well as higher levels of personal importance, and engaged in rehearsal more than Leave participants did. These two groups also differed in their memory performance. Specifically, Remain participants were initially just as confident and consistent in their memories three months after the referendum results as Leave participants. However, over time, participants who voted to remain became more consistent but less confident in their memory for the EU referendum results than those who voted to leave. This was true even when we re-coded the data to allow for less specific memories and/or memories with more/less detail to be considered consistent (see S-Table 4). 
These results are consistent with previous laboratory findings in which negative emotion has been associated with greater memory consistency and/or event accuracy (Bohn \& Berntsen, 2007; Holland \& Kensinger, 2012) and positive emotion has been associated with greater confidence (Holland \& Kensinger, 2012; Kensinger \& Schacter, 2006b; Levine \& Bluck, 2004). Recent experimental research has also demonstrated that relative to positive emotion, negative emotion enhances the mnemonic precision (Cooper et al., 2019; Xie \& Zhang, 2017). One theory which explains this valence effect is the affect-as-information framework (Clore et al., 2001) which suggests that positive and negative valence have differing effects on how we process information; in particular, positive valence is associated with focus on global characteristics of the event and less accurate memory for details, while negative valence is associated with increased sensory details that are stored, maintained and remembered (Bowen et al., 2018). Thus, overconfidence among Leave participants compared to Remain participants and greater memory consistency in Remain participants compared to Leave participants, may be due to the effects of valence on the way these participants processed the event. In line with this idea, in our mediation analysis, we found that higher levels of positive emotion experienced at Survey 1 among Leave participants led to less consistent memory for them than Remain participants. Although we did not find significant effects of negative emotion, these results corroborate previous laboratory findings and suggest that mnemonic disadvantage of positive relative to negative emotion can be extended to memories for real life events.

In addition to positive emotion, our mediation analysis also highlighted the role of rehearsal. Specifically, higher initial rehearsal levels at Survey 1 among Remain enabled them to maintain more consistent memories even after a long-term delay. Although it has not always been found to predict memory consistency and/or accuracy (Day \& Ross, 2014; Hirst et al., 2009; Kensinger et al., 2005; Kvavilashvili et al., 2003; Pillemer, 1984), rehearsal has 
been implicated as an important factor in maintaining flashbulb memories (Bohannon, 1988; Neisser et al., 1996). In particular, it has often been highlighted in studies examining positive and negative flashbulb memories because positive events are often spontaneously rehearsed more than negative ones (Berntsen \& Thomsen, 2005; Breslin \& Safer, 2011; Tekcan, 2001; Walker et al., 2009). While these patterns are the opposite from what we saw in this study (where Leave participants who experienced positive emotion engaged in less rehearsal than Remain participants who experienced negative emotion), it is important to note that the effects of valence on rehearsal depend on the conditions after the event, such as increased media attention (Breslin \& Safer, 2011). In the UK "Brexit"5 headlines have dominated the news not only in the immediate aftermath of the Referendum but also for several years after. This means that our UK participants were likely to have been faced with constant reminders of Brexit irrespective of whether they initially experienced positive or negative emotion. We have shown here that in such situations when the amount of external reminders is similar following an event, negative memories can be initially rehearsed more which could lead to greater memory consistency and higher memory vividness.

In contrast to memory consistency, we did not find any significant mediators for the group differences in the slope of memory confidence - a key distinguishing feature of flashbulb memories (Talarico \& Rubin, 2003, 2017). More specifically, our initial analysis showed that participants who voted to leave tended to maintain higher confidence for their memory than those who voted to remain (Figure 3B). Yet, when we tested the effects of emotional responses, surprise, importance and rehearsal in our mediation analysis, none of them significantly mediated this group effect. This was in contrast with previous findings from Day and Ross (2014) in which memory confidence was associated with surprise,

\footnotetext{
${ }^{5}$ An abbreviation for "British exit" used to describe the United Kingdom's decision in 2016 to withdraw its European Union membership.
} 
rehearsal, and emotional response. One possible explanation for the lack of significant mediators in our study is that some of the mediators included in the model did play a role but our sample size was too small to detect their effects; in fact, our sample size was determined to have sufficient statistical power to detect the group differences but not to detect such mediation effects (see Participants and Recruitment). But it is also possible that the group difference in memory confidence comes from group differences during retrieval rather than group differences during encoding, such as differences in the ease of retrieval or in the social expectations concerning what one ought to remember (Echterhoff \& Hirst, 2006). Future research needs to include a larger number of participants with more comprehensive assessments of factors relevant to retrieval to understand how differently positive vs. negative public events affect memory confidence.

Another important aspect of memory investigated in the literature on emotion and memory is vividness. Our analyses on memory vividness revealed that Leave and Remain participants showed similar rates of decline in their memory vividness over time but Leave participants initially had lower ratings relative to Remain participants. This result may appear to suggest that positive emotion experienced by Leave participants has an impairing effect on memory vividness. However, a subsequent mediation analysis suggested a more complex pattern, indicating that this group difference was due to the competing effects of positive emotion, rehearsal and importance. Specifically, Leave participants experienced stronger positive emotion which in turn significantly led to more vivid memories. However, Leave participants also perceived the event as less important and engaged in rehearsal less than Remain participants did, which led to less vivid memories. The results were also replicated after including other control variables, such as age and education (see Supplemental Results).

In summary, we found that positive and negative public events are remembered differently, both initially and after a long-term delay by assessing individuals' memory for 
the UK's EU Referendum. Remain participants who experienced negative emotion maintained more consistent memories even after 16 months, compared to Leave participants who experienced positive emotion. This difference between the two voting groups appears to be driven not only by differences in their emotional experiences but also by differences in rehearsal. Despite being less consistent, Leave participants maintained higher levels of memory confidence than Remain participants. In addition, we found that positive emotion, rehearsal, and perceived importance all affect how vividly individuals remembered their circumstances in which they found the referendum result. Thus, it appears that memories for emotional public events are supported by several pathways beyond the effects of emotion. Nevertheless, as described above, our sample size was modest for mediation analyses. Thus, results from the series of mediation analyses need to be interpreted with caution; future studies with a larger number of participants are needed to confirm the effects of potential factors observed in this study.

While our results are consistent with previous studies on valence on memory (Kensinger et al., 2006; Kensinger \& Schacter, 2006b; Levine \& Bluck, 2004; Ochsner, 2000), it is also possible that they are not necessarily being driven by valence. For instance, while the event was the same for the two UK voting groups, the outcome and implications may not have been. According to Brown's transition theory (2016), an event which is perceived to mark the end to life as it was previously known is effective in facilitating the formation and maintenance of autobiographical memories. For UK participants, the result of the referendum indicated possible changes to many things including current legislation, the rights of European Union citizens, public trade practices and immigration rights, to name a few. Participants who voted to remain in the UK may have perceived these changes as more significant than those who voted to leave in the UK as they are inconsistent with their wishes. In line with this idea, when we asked the perceived changes due to the referendum result in 
this study ("Since the EU Referendum results has your life got better, got worse or stayed the same?") in Survey 2, Leave participants were more likely to say that their lives had stayed the same compared with Remain participants (92\% vs. 79\%; see Supplemental results). Thus, Remain participants may have felt that the referendum results had a more direct impact on their current lives than Leave participants did, which may have affected their memory performance. However, it should be noted that previous studies demonstrate consistent, vivid and confident memories for emotional events even when the events are not associated with life transitions. For example, several studies have found evidence of vivid memory formation following sporting events (e.g. Breslin \& Safer, 2011; Kensinger \& Schacter, 2006b; Talarico $\&$ Moore, 2012) which are unlikely to have been significant enough to bring about change to an individual's daily life. Future studies need to test the effects of perceived changes, emotional valence and their interaction on memory formation and maintenance to address the role of each factor systematically.

Another factor which may have played a role is arousal. In other words, while valence differed between the two UK voting groups, so too could levels of arousal which may affect long-term memory accuracy. Arousing information relative to non-arousing information is consolidated more effectively (LaBar \& Phelps, 1998) through the activation of the noradrenergic system and the hippocampal memory formation, resulting in a more stable memory over time (McGaugh, 2000, 2004). Emotional arousal can also lead to selective memory in which the salient/central details of the event are remembered better but at the expense of the non-central details (e.g. central vs. peripheral trade-off; Kensinger et al., 2007). Since negative events are often associated with stronger arousal levels than positive events (Kuppens et al., 2013; Warriner et al., 2013) this may explain why over time, Remain participants held more consistent memories than Leave participants did. However, as we did not obtain measures of arousal in the current study, we do not know whether levels of arousal 
contributed to the long-term differences in memory consistency. Future research investigating memories for a positive vs. negative event should also include measures of arousal.

There are also several important limitations that need to be mentioned. The first limitation of the current study is that due to its nature, we could not randomly assign participants to the two voting groups or the control group (US participants), meaning that the results may simply reflect the characteristics of the people who voted to leave or remain in the EU referendum rather than reflecting the effects of valence. In fact, the two groups were significantly different in their age, gender and levels of education. In addition to these demographic variables, another possible factor that could affect our results is the recruitment method. Specifically, Remain participants included more undergraduate students than Leave participants who were often recruited via Prolific. On the one hand, this observation is consistent with the general voting behavior seen in UK residents: UK residents with university degrees and those of a younger age were less likely to vote Leave (Alabrese et al., 2019). In our supplemental analyses, we also confirmed that controlling for age, gender and education did not change our overall results (see Supplemental Results). Nevertheless, it is possible that the effects of valence we observed are driven by other factors than valence. In addition, the three groups of participants were different in their political orientation; such that Leave participants supported conservative political parties more than Remain participants and US participants. Thus, it is difficult to establish the causal effects of valence and group identity from our results.

Additionally, we do not have a representative sample in our UK or US participants and it is possible that we recruited and retained individuals who were more interested in the political consequences of the referendum or those who welcomed the opportunity to share their memories and thoughts (i.e., self-selection bias; Heckman, 1990). In fact, when we compared those who completed Survey 1 and returned in later surveys vs. those who dropped 
out after completing Survey 1, returning participants reported higher levels of initial rehearsal than those who dropped out. Thus, we may have retained a subset of participants who had stronger commitment to follow up the event. We also found other differences between the two groups of participants in their age, education and positive emotion. Thus, our results are unlikely to represent the effects of voting choice and emotion across all UK voters.

Thirdly, we included US participants as a control group based on similar methods used in other studies (e.g. defining groups based on different nationalities; Conway et al., 1994; Curci et al., 2001; Kvavilashvili et al., 2003; Luminet et al., 2004; Tinti et al., 2009). Having a control group allowed us to test the effects of social identity on memory for the same event (Berntsen, 2018). Yet it is important to acknowledge the differences between UK and US participants beyond their social identity. For example, UK participants, relative to US participants, may have had a better understanding of the historical background of the referendum, and been exposed to more media coverage of the event. Moreover, we did not control for the time at which participants learnt the EU referendum results. Given the event's political nature, results from each region within the UK became available whenever counting of the votes within the region was complete up until the official results across the UK were published early the following day. This is potentially problematic when also considering the time difference between the two countries. For many participants in the UK, the referendum outcome was released in the morning; meaning that they learned of the results right after waking up. In contrast, for those in the US, it was more likely that they learned of the results during the evening. Thus, the difference between our UK and US participants in their memory measures could have been due to these other factors.

In contrast, one of our main focuses of this paper was to examine the differences between UK participants who perceived the event as positive vs. those who perceived the event as negative in their memories. Since both groups of participants lived in the UK, 
comparisons between these two groups are less likely to be affected by these factors. Nevertheless, some UK participants said that they made a conscious effort to watch the results throughout the night; these participants could have learned the results of individual regions first and may have been able to predict the outcome before the results were officially announced. In contrast, others woke up to the news. Between these two sub-groups of participants, levels of surprise may differ, causing differences in the way in which the memories were encoded. In addition, when it came to asking participants questions about where they were and what they were doing etc., participants who stayed up to watch the results, may have provided us with information relating to a different time compared to their initial report. In other words, it is possible that those who monitored the results throughout the night could have two memories regarding the reception event: one for the time before the results were official (i.e., while watching the live footage) and one for after. In the current study, we did not obtain information about whether participants stayed awake all night to monitor the results or not.

Another important question for future research concerns rehearsal. Our measure of rehearsal includes both overt- (e.g., talking to others about it or watching the media) and covert rehearsal (e.g., thinking about it) as well as an item that indicates how much time they spent on the internet. Participants' responses to these four items were highly correlated as indicated by the high internal consistency (see Method). When we separately computed measures on covert (thinking about) vs. overt rehearsal (talking to others about it, watching the media or looking on the internet), they were highly correlated with each other at Survey $1: r(554)=.85, \mathrm{p}<.01$. Thus, it was difficult to test their independent effects on our memory measures in this study. However, other studies have argued that overt rehearsal is associated with more consistent memories than covert rehearsal (Hornstein et al., 2003; Koppel et al., 
2013). Future research is therefore needed to test the effects of covert and overt rehearsal on memories for positive vs. negative public events.

Finally, it is also worth noting that over the course of the survey period, the UK underwent two significant political events including the official intention of the UK to leave the EU within two years (i.e., the triggering of Article 50) on $29^{\text {th }}$ March, 2017 and a general election on $8^{\text {th }}$ June, 2017 in which the current governing party lost its majority, resulting in the formation of a minority government. Both of these events dominated the news and as such may have influenced participants' emotional reactions and/or memories.

In summary, the current study provides evidence that memories surrounding the personal circumstances of a significant event that is either interpreted as positive or negative can be remembered with a great deal of consistency, vividness and confidence over a year later. Furthermore, the results suggest that valence can yield different outcomes on memory measures both in the short- and the long-term, and corroborate previous findings whereby negative emotion has been associated with better memory consistency while positive emotion has been associated with over-confidence (Kensinger et al., 2006). We also found that differences in memory between those who found the event as positive vs. negative are not only due to emotion, but also due to rehearsal and perceived personal importance. Our findings highlight the importance of considering rehearsal, importance and the time between the event and when memory measures are obtained when interpreting how individuals remember public events. 


\section{References}

Alabrese, E., Becker, S. O., Fetzer, T., \& Novy, D. (2019). Who voted for Brexit? Individual and regional data combined. European Journal of Political Economy. https://doi.org/10.1016/j.ejpoleco.2018.08.002

Barnes, P. (2016). EU referendum poll tracker. https://www.bbc.co.uk/news/uk-politics-eureferendum-36271589

Berntsen, D. (2009). Flashbulb memory and social identity. In O. Luminet \& A. Curci (Eds.), Flashbulb memories: New issues and new perspectives (pp. 187-205). Psychology Press. https://psycnet.apa.org/record/2008-07509-009

Berntsen, D., \& Thomsen, D. K. (2005). Personal memories for remote historical events: Accuracy and clarity of flashbulb memories related to World War II. Journal of Experimental Psychology: General, 134(2), 242-257. https://doi.org/10.1037/00963445.134.2.242

Bohannon, J. N. (1988). Flashbulb memories for the space shuttle disaster: A tale of two theories. Cognition, 29(2), 179-196. https://doi.org/10.1016/0010-0277(88)90036-4

Bohn, A., \& Berntsen, D. (2007). Pleasantness bias in flashbulb memories: Positive and negative flashbulb memories of the fall of the Berlin Wall among East and West Germans. Memory and Cognition, 35(3), 565-577. https://doi.org/10.3758/BF03193295

Bowen, H. J., Kark, S. M., \& Kensinger, E. A. (2018). NEVER forget: negative emotional valence enhances recapitulation. In Psychonomic Bulletin and Review. https://doi.org/10.3758/s13423-017-1313-9

Bowen, H. J., \& Kensinger, E. A. (2017). Recapitulation of emotional source context during memory retrieval. Cortex. https://doi.org/10.1016/j.cortex.2016.11.004

Breslin, C. W., \& Safer, M. A. (2011). Effects of event valence on long-term memory for two baseball championship games. Psychological Science, 22(11), 1408-1412. 
https://doi.org/10.1177/0956797611419171

Brown, N. R. (2016). Transition Theory: A Minimalist Perspective on the Organization of Autobiographical Memory. Journal of Applied Research in Memory and Cognition, 5(2), 128-134. https://doi.org/10.1016/j.jarmac.2016.03.005

Brown, R., \& Kulik, J. (1977). Flashbulb memories. Cognition, 5, 73-99.

Browne, M. W., \& Cudeck, R. (1993). Alternative ways of assessing model fit. In K. A. Bollen \& J. S. Long (Eds.), Testing Structural Equation Models (pp. 136-162). Sage Publications, Inc.

Chandler, J. J., \& Paolacci, G. (2017). Lie for a Dime: When Most Prescreening Responses Are Honest but Most Study Participants Are Impostors. Social Psychological and Personality Science. https://doi.org/10.1177/1948550617698203

Christianson, S. Á. (1989). Flashbulb memories: Special, but not so special. Memory \& Cognition, 17, 435-443. https://doi.org/10.3758/BF03202615

Clore, G. L., Wyer, R. S., Dienes, B., Gasper, K., Gohm, C., \& Isbell, L. (2001). Affective feelings as feedback: Some cognitive consequences. In L. L. Martin \& G. L. Clore (Eds.), Theories of mood and cognition: A user's guidebook (pp. 27-62). Erlbaum.

Conway, M. A., Anderson, S. J., Larsen, S. F., Donnelly, C. M., McDaniel, M. A., McClelland, A. G. R., Rawles, R. E., \& Logie, R. H. (1994). The formation of flashbulb memories. Memory \& Cognition, 22(3), 326-343. https://doi.org/10.3758/BF03200860

Cooper, R. A., Kensinger, E. A., \& Ritchey, M. (2019). Memories Fade: The Relationship Between Memory Vividness and Remembered Visual Salience. Psychological Science, 30(5), 657-668. https://doi.org/10.1177/0956797619836093

Curci, A., \& Luminet, O. (2006). Follow-up of a cross-national comparison on flashbulb and event memory for the September 11th attacks. Memory, 14(3), 329-344. https://doi.org/10.1080/09658210500340816 
Curci, A., Luminet, O., Finkenauer, C., \& Gisle, L. (2001). Flashbulb memories in social groups: A comparative test-retest study of the memory of French President Mitterrand's death in a French and a Belgian group. Memory, 9(2), 81-101. https://doi.org/10.1080/09658210042000120

D’Argembeau, A., Comblain, C., \& van der Linden, M. (2003). Phenomenal characteristics of autobiographical memories for positive, negative, and neutral events. Applied Cognitive Psychology, 17(3), 281-294. https://doi.org/10.1002/acp.856

Day, M. V., \& Ross, M. (2014). Predicting confidence in flashbulb memories. Memory, 22(3), 232-242. https://doi.org/10.1080/09658211.2013.778290

Demiray, B., \& Freund, A. M. (2015). Michael Jackson, Bin Laden and I: Functions of positive and negative, public and private flashbulb memories. Memory, 23(4), 487-506. https://doi.org/10.1080/09658211.2014.907428

Destun, L. M., \& Kuiper, N. A. (1999). Phenomenal Characteristics Associated with Real and Imagined Events: The Effects of Event Valence and Absorption. Applied Cognitive Psychology, 13(2), 175-186. https://doi.org/10.1002/(sici)10990720(199904)13:2<175::aid-acp552>3.0.co;2-w

Dewhurst, S. A., \& Parry, L. A. (2000). Emotionality, distinctiveness, and recollective experience. European Journal of Cognitive Psychology, 12(4), 541-551. https://doi.org/10.1080/095414400750050222

Dolcos, F., \& Cabeza, R. (2002). Event-related potentials of emotional memory: Encoding pleasant, unpleasant, and neutral pictures. Cognitive, Affective and Behavioral Neuroscience, 2(3), 252-263. https://doi.org/10.3758/CABN.2.3.252

Dolcos, F., Labar, K. S., \& Cabeza, R. (2004). Dissociable effects of arousal and valence on prefrontal activity indexing emotional evaluation and subsequent memory: An eventrelated fMRI study. NeuroImage, 23(1), 64-74. 
https://doi.org/10.1016/j.neuroimage.2004.05.015

Dolcos, F., Labar, K. S., \& Cabeza, R. (2005). Remembering one year later: Role of the amygdala and the medial temporal lobe memory system in retrieving emotional memories. Proceedings of the National Academy of Sciences of the United States of America, 102(7), 2626-2631. https://doi.org/10.1073/pnas.0409848102

Duncan, T. E., Duncan, S. C., \& Strycker, L. A. (2006). An introduction to latent variable growth curve modeling : concepts, issues, and applications. (2nd ed.). Erlbaum. https://doi.org/https://doi.org/10.4324/9780203879962

Echterhoff, G., \& Hirst, W. (2006). Thinking about memories for everyday and shocking events: Do people use ease-of-retrieval cues in memory judgments? Memory and Cognition, 34(4), 763-775. https://doi.org/10.3758/BF03193424

Er, N. (2003). A new flashbulb memory model applied to the Marmara earthquake. Applied Cognitive Psychology, 17(5), 503-517. https://doi.org/10.1002/acp.870

Finkenauer, C., Luminet, O., Gisle, L., El-Ahmadi, A., Van Der Linden, M., \& Philippot, P. (1998). Flashbulb memories and the underlying mechanisms of their formation: Toward an emotional-integrative model. Memory and Cognition, 26(3), 516-531. https://doi.org/10.3758/BF03201160

Fontaine, J. R. J., Scherer, K. R., Roesch, E. B., \& Ellsworth, P. C. (2007). The world of emotions is not two-dimensional. Psychological Science, 18(12), 1050-1057. https://doi.org/10.1111/j.1467-9280.2007.02024.x

Ford, J. H., Addis, D. R., \& Giovanello, K. S. (2012). Differential effects of arousal in positive and negative autobiographical memories. Memory, 20(7), 771-778. https://doi.org/10.1080/09658211.2012.704049

Fredrickson, B. L., \& Branigan, C. (2005). Positive emotions broaden the scope of attention and thought-action repertoires. Cognition and Emotion, 19(3), 313-332. 
https://doi.org/10.1080/02699930441000238

Heckman, J. J. (1990). Selection Bias and Self-selection. In Econometrics (pp. 201-224).

Palgrave Macmillan UK. https://doi.org/10.1007/978-1-349-20570-7_29

Hirst, W., Phelps, E. A., Buckner, R. L., Budson, A. E., Cuc, A., Gabrieli, J. D. E., Johnson, M. K., Lustig, C., Lyle, K. B., Mather, M., Meksin, R., Mitchell, K. J., Ochsner, K. N., Schacter, D. L., Simons, J. S., \& Vaidya, C. J. (2009). Long-Term Memory for the Terrorist Attack of September 11: Flashbulb Memories, Event Memories, and the Factors That Influence Their Retention. Journal of Experimental Psychology: General, 138(2), 161-176. https://doi.org/10.1037/a0015527

Hirst, W., Phelps, E. A., Buckner, R. L., Johnson, M. K., Lyle, K. B., Mather, M., \& Mitchell, K. J. (2010). Influence Their Retention. Journal of Experimental Psychology. General, 138(2), 161-176. https://doi.org/10.1037/a0015527.Long-term

Hirst, W., Phelps, E. A., Meksin, R., Vaidya, C. J., Johnson, M. K., Mitchell, K. J., Buckner, R. L., Budson, A. E., Gabrieli, J. D. E., Lustig, C., Mather, M., Ochsner, K. N., Schacter, D., Simons, J. S., Lyle, K. B., Cuc, A. F., \& Olsson, A. (2015). A ten-year follow-up of a study of memory for the attack of september 11, 2001: Flashbulb memories and memories for flashbulb events. Journal of Experimental Psychology: General, 144(3), 604-623. https://doi.org/10.1037/xge0000055

Hirst, W., Yamashiro, J. K., \& Coman, A. (2018). Collective Memory from a Psychological Perspective. Trends in Cognitive Sciences, 22(5), 438-451.

https://doi.org/10.1016/j.tics.2018.02.010

Holland, A. C., \& Kensinger, E. A. (2012). Younger, middle-aged, and older adults’ memories for the 2008 U.S. Presidential Election. Journal of Applied Research in Memory and Cognition, 1(3), 163-170. https://doi.org/10.1016/j.jarmac.2012.06.001 Hornstein, S. L., Brown, A. S., \& Mulligan, N. W. (2003). Long-term flashbulb memory for 
learning of Princess Diana's death. Memory, 11(3), 293-306.

https://doi.org/10.1080/09658210244000063

Keightley, M. L., Chiew, K. S., Anderson, J. A. E., \& Grady, C. L. (2011). Neural correlates of recognition memory for emotional faces and scenes. Social Cognitive and Affective Neuroscience. https://doi.org/10.1093/scan/nsq003

Keith, M. G., Tay, L., \& Harms, P. D. (2017). Systems perspective of amazon mechanical turk for organizational research: Review and recommendations. In Frontiers in Psychology. https://doi.org/10.3389/fpsyg.2017.01359

Kensinger, E. A. (2009). Remembering the details: Effects of emotion. In Emotion Review. https://doi.org/10.1177/1754073908100432

Kensinger, E. A., Garoff-Eaton, R. J., \& Schacter, D. L. (2006). Memory for specific visual details can be enhanced by negative arousing content. Journal of Memory and Language, 54, 99-112. https://doi.org/10.1016/j.jml.2005.05.005

Kensinger, E. A., Garoff-Eaton, R. J., \& Schacter, D. L. (2007). Effects of emotion on memory specificity: Memory trade-offs elicited by negative visually arousing stimuli. Journal of Memory and Language. https://doi.org/10.1016/j.jml.2006.05.004

Kensinger, E. A., Krendl, A., \& Corkin, S. (2005). Memories of an emotional and a nonemotional event: Effects of aging and delay interval. Experimental Aging Research, 32(1), 23-45. https://doi.org/10.1080/01902140500325031

Kensinger, E. A., \& Schacter, D. L. (2006a). Processing emotional pictures and words: Effects of valence and arousal. Cognitive, Affective and Behavioral Neuroscience, 6(2), 110-126. https://doi.org/10.3758/CABN.6.2.110

Kensinger, E. A., \& Schacter, D. L. (2006b). When the Red Sox shocked the Yankees: Comparing negative and positive memories. Psychonomic Bulletin and Review, 13(5), 757-763. https://doi.org/10.3758/BF03193993 
Kline, R. B. (2016). Principles and practice of structural equation modeling, 4th ed. In Principles and practice of structural equation modeling, 4th ed. Guilford Publications.

Kopietz, R., \& Echterhoff, G. (2014). Remembering the 2006 Football World Cup in Germany: Epistemic and social consequences of perceived memory sharedness. Memory Studies, 7(3), 298-313. https://doi.org/10.1177/1750698014530620

Koppel, J., Brown, A. D., Stone, C. B., Coman, A., \& Hirst, W. (2013). Remembering President Barack Obama's inauguration and the landing of US Airways Flight 1549: A comparison of the predictors of autobiographical and event memory. Memory, 21(7), 798-806. https://doi.org/10.1080/09658211.2012.756040

Kraha, A., \& Boals, A. (2014). Why so negative? Positive flashbulb memories for a personal event. Memory, 22(4), 442-449. https://doi.org/10.1080/09658211.2013.798121

Kraha, A., Talarico, J. M., \& Boals, A. (2014). Unexpected positive events do not result in flashbulb memories. Applied Cognitive Psychology, 28(4), 579-589. https://doi.org/10.1002/acp.3039

Kuppens, P., Tuerlinckx, F., Russell, J. A., \& Barrett, L. F. (2013). The relation between valence and arousal in subjective experience. Psychological Bulletin, 139(4), 917-940. https://doi.org/10.1037/a0030811

Kvavilashvili, L., Mirani, J., Schlagman, S., Foley, K., \& Kornbrot, D. E. (2009). Consistency of flashbulb memories of September 11 over long delays: Implications for consolidation and wrong time slice hypotheses. Journal of Memory and Language, 61(4), 556-572. https://doi.org/10.1016/j.jml.2009.07.004

Kvavilashvili, L., Mirani, J., Schlagman, S., \& Kornbrot, D. E. (2003). Comparing flashbulb memories of September 11 and the death of Princess Diana: Effects of time delays and nationality. Applied Cognitive Psychology, 17(9), 1017-1031. https://doi.org/10.1002/acp.983 
LaBar, K. S., \& Cabeza, R. (2006). Cognitive neuroscience of emotional memory. Nature Reviews Neuroscience, 7, 54-64. https://doi.org/10.1038/nrn1825

LaBar, K. S., \& Phelps, E. A. (1998). Arousal-mediated memory consolidation: Role of the Medial Temporal Lobe in Humans. Psychological Science, 9(6), 490-493. https://doi.org/10.1111/1467-9280.00090

Levine, L. J., \& Bluck, S. (2004). Painting with broad strokes: Happiness and the malleability of event memory. Cognition and Emotion, 18(4), 559-574. https://doi.org/10.1080/02699930341000446

Levine, L. J., \& Edelstein, R. S. (2009). Emotion and memory narrowing: A review and goalrelevance approach. Cognition \& Emotion, 23(5), 833-875. https://doi.org/10.1080/02699930902738863

Liu, A., Ying, X., \& Luo, J. (2012). The Flashbulb Memory of the Positive and Negative Events : Wenchuan Earthquake and Acceptance to College. International Journal of Social, Behavioral, Educational, Economic, Business and Industrial Engineering, 6(5), $49-54$.

Luminet, O., Curci, A., Marsh, E. J., Wessel, I., Constantin, T., Gencoz, F., \& Yogo, M. (2004). The Cognitive, emotional, and social impacts of the september 11 attacks: Group differences in memory for the reception context and the determinants of flashbulb memory. Journal of General Psychology, 131(3), 197-224. https://doi.org/10.3200/GENP.131.3.197-224

Madan, C. R., Caplan, J. B., Lau, C. S. M., \& Fujiwara, E. (2012). Emotional arousal does not enhance association-memory. Journal of Memory and Language. https://doi.org/10.1016/j.jml.2012.04.001

Madan, C. R., Scott, S. M. E., \& Kensinger, E. A. (2019). Positive emotion enhances association-memory. Emotion. https://doi.org/10.1037/emo0000465 
Mather, M., \& Sutherland, M. (2009). Disentangling the effects of arousal and valence on memory for intrinsic details. Emotion Review, 1(2), 118-119. https://doi.org/10.1177/1754073908100435

McGaugh, J. L. (2000). Memory - A century of consolidation. Science, 287(5451), 248-251. https://doi.org/10.1126/science.287.5451.248

McGaugh, J. L. (2004). Memory reconsolidation hypothesis revived but restrained: Theoretical comment on Biedenkapp and Rudy (2004). In Behavioral Neuroscience. https://doi.org/10.1037/0735-7044.118.5.1140

Merck, C., Yamashiro, J. K., \& Hirst, W. (2020). Remembering the big game: social identity and memory for media events. Memory, 28(6), 795-814. https://doi.org/10.1080/09658211.2020.1784232

Mickley, K. R., \& Kensinger, E. A. (2008). Emotional valence influences the neural correlates associated with remembering and knowing. Cognitive, Affective and Behavioral Neuroscience, 8(2), 143-152. https://doi.org/10.3758/CABN.8.2.143

Nashiro, K., Sakaki, M., \& Mather, M. (2012). Age differences in brain activity during emotion processing: Reflections of age-related decline or increased emotion regulation? Gerontology, 58(2), 156-163. https://doi.org/10.1159/000328465

Neisser, U., \& Harsch, N. (1992). Phantom flashbulbs: False recollections of hearing the news about Challenger. In Affect and accuracy in recall (pp. 9-31). Cambridge University Press. https://doi.org/10.1017/cbo9780511664069.003

Neisser, U., Winograd, E., Bergman, E. T., Schreiber, C. A., Palmer, S. E., \& Weldon, M. S. (1996). Remembering the Earthquake: Direct Experience vs. Hearing the News. Memory, 4(4), 337-357. https://doi.org/10.1080/096582196388898

Ochsner, K. N. (2000). Are affective events richly recollected or simply familiar? The experience and process of recognizing feelings past. Journal of Experimental 
Psychology: General, 129(2), 242-261. https://doi.org/10.1037/0096-3445.129.2.242

Páez, D., Mathias, A., Cavalli, S., Guichard, E., Pizarro, J. J., Méndez, L., \& El-Astal, S.

(2018). Flashbulb memories and collective memories: psychosocial processes related to rituals, emotions, and memories. In Flashbulb Memories: New Challenges and Future Perspectives. (pp. 219-239). Psychology Press. https://doi.org/10.4324/9781315623481-

12

Pillemer, D. B. (1984). Flashbulb memories of the assassination attempt on President Reagan. Cognition, 16(1), 63-80. https://doi.org/10.1016/0010-0277(84)90036-2

Rosseel, Y. (2012). Lavaan: An R package for structural equation modeling. Journal of Statistical Software. https://doi.org/10.18637/jss.v048.i02

Sakaki, M., Raw, J., Findlay, J., \& Thottam, M. (2019). Advanced aging enhances the positivity effect in memory: Due to cognitive control or age-related decline in emotional processing? Collabra: Psychology., 5(1), 49.

https://doi.org/http://doi.org/10.1525/collabra.222

Schaefer, A., \& Philippot, P. (2005). Selective effects of emotion on the phenomenal characteristics of autobiographical memories. Memory, 13(2), 148-160. https://doi.org/10.1080/09658210344000648

Schaefer, E. G., Halldorson, M. K., \& Dizon-Reynante, C. (2011). TV or not TV? does the immediacy of viewing images of a momentous news event affect the quality and stability of flashbulb memories? Memory, 19(3), 251-266.

https://doi.org/10.1080/09658211.2011.558512

Schmolck, H., Buffalo, E. a, \& Squire, L. R. (2000). Memory Distortions Develop Over Time : Psychological Science, 11(1), 39-45.

Schümann, D., Bayer, J., Talmi, D., \& Sommer, T. (2018). Dissociation of immediate and delayed effects of emotional arousal on episodic memory. Neurobiology of Learning 
and Memory, 148, 11-19. https://doi.org/10.1016/j.nlm.2017.12.007

Shapiro, D. N., Chandler, J., \& Mueller, P. A. (2013). Using Mechanical Turk to Study

Clinical Populations. Clinical Psychological Science, 1(2), 213-220.

https://doi.org/10.1177/2167702612469015

Sharot, T., Delgado, M. R., \& Phelps, E. A. (2004). How emotion enhances the feeling of remembering. Nature Neuroscience. https://doi.org/10.1038/nn1353

Sharot, T., Verfaelli, M., \& Yonelinas, A. P. (2007). How emotion strengthens the recollective experience: A time-dependent hippocampal process. PLOS ONE. https://doi.org/10.1371/journal.pone.0001068

Spachtholz, P., Kuhbandner, C., \& Pekrun, R. (2014). Negative affect improves the quality of memories: Trading capacity for precision in sensory and working memory. Journal of Experimental Psychology: General, 143(4), 1450-1456.

https://doi.org/10.1037/xge0000012

Stone, C. B., Luminet, O., \& Takahashi, M. (2015). Remembering Public, Political Events: A Cross-Cultural and -Sectional Examination of Australian and Japanese Public

Memories. Applied Cognitive Psychology, 29(2), 280-290. https://doi.org/10.1002/acp.3106

Storbeck, J., \& Clore, G. L. (2005). With sadness comes accuracy; with happiness, false memory: Mood and the false memory effect. Psychological Science, 16(10), 785-791. https://doi.org/10.1111/j.1467-9280.2005.01615.x

Tajfel, H. (1982). The social psychology of intergroup relations. In Annual Review of Psychology (Vol. 33, Issue 1, pp. 1-39). Taylor and Francis Inc. https://doi.org/10.1146/annurev.ps.33.020182.000245

Talarico, J. M., Bohn, A., \& Wessel, I. (2019). The role of event relevance and congruence to social groups in flashbulb memory formation. Memory, 27(7), 985-997. 
https://doi.org/10.1080/09658211.2019.1616097

Talarico, J. M., Labar, K. S., \& Rubin, D. C. (2004). Emotional intensity predicts autobiographical memory experience. Memory and Cognition, 32(7), 1118-1132. https://doi.org/10.3758/BF03196886

Talarico, J. M., \& Moore, K. M. (2012). Memories of "the rivalry": Differences in how fans of the winning and losing teams remember the same game. Applied Cognitive Psychology, 26(5), 746-756. https://doi.org/10.1002/acp.2855

Talarico, J. M., \& Rubin, D. C. (2003). Confidence, not consistency, characterizes flashbulb memories. Psychological Science, 14(5), 455-461. https://doi.org/10.1111/14679280.02453

Talarico, J. M., \& Rubin, D. C. (2007). Flashbulb memories are special after all; in phenomenology, not accuracy. Applied Cognitive Psychology: The Official Journal of the Society for Applied Research in Memory and Cognition, 21(5), 557-578. https://doi.org/10.1002/acp.1293

Talarico, J. M., \& Rubin, D. C. (2008). Flashbulb memories result from ordinary memory processes and extraordinary event characteristics. Flashbulb Memories: New Issues and New Perspectives, January 2009, 79-97. https://doi.org/10.4324/9780203889930

Talarico, J. M., \& Rubin, D. C. (2017). Ordinary memory processes shape Flashbulb memories of extraordinary events. In Flashbulb Memories (pp. 73-95). Psychology Press. https://doi.org/10.4324/9781315623481-5

Talmi, D. (2013). Enhanced emotional memory: Cognitive and neural mechanisms. Current Directions in Psychological Science, 22(6), 430-436. https://doi.org/Doi $10.1177 / 0963721413519415$

Tekcan, A. I. (2001). Flashbulb memories for a negative and a positive event: News of Desert Storm and acceptance to college. Psychological Reports, 88(2), 323-331. 
https://doi.org/10.2466/pr0.2001.88.2.323

The Electoral Commission. (2016). EU referendum results. Https://Www.Bbc.Co.Uk/News. https://www.electoralcommission.org.uk/find-information-by-subject/elections-andreferendums/past-elections-and-referendums/eu-referendum/electorate-and-countinformation

Tinti, C., Schmidt, S., Testa, S., \& Levine, L. J. (2014). Distinct processes shape flashbulb and event memories. Memory and Cognition, 42(4), 539-551. https://doi.org/10.3758/s13421-013-0383-9

Todd, R. M., Talmi, D., Schmitz, T. W., Susskind, J., \& Anderson, A. K. (2012). Psychophysical and neural evidence for emotion-enhanced perceptual vividness. Journal of Neuroscience. https://doi.org/10.1523/JNEUROSCI.0155-12.2012

Walker, W. R., Skowronski, J. J., Gibbons, J. A., Vogl, R. J., \& Ritchie, T. D. (2009). Why people rehearse their memories: Frequency of use and relations to the intensity of emotions associated with autobiographical memories. Memory. https://doi.org/10.1080/09658210903107846

Walker, W. R., Skowronski, J. J., \& Thompson, C. P. (2003). Life is Pleasant - And Memory Helps to Keep It that Way! Review of General Psychology. https://doi.org/10.1037/1089-2680.7.2.203

Warriner, A. B., Kuperman, V., \& Brysbaert, M. (2013). Norms of valence, arousal, and dominance for 13,915 English lemmas. Behavior Research Methods, 45(4), 1191-1207. https://doi.org/10.3758/s13428-012-0314-x

Xie, W., \& Zhang, W. (2016). Negative emotion boosts quality of visual working memory representation. Emotion. https://doi.org/10.1037/emo0000159

Xie, W., \& Zhang, W. (2017). Negative emotion enhances mnemonic precision and subjective feelings of remembering in visual long-term memory. Cognition, 166, 73-83. 
https://doi.org/10.1016/j.cognition.2017.05.025 
Table 1.

Demographic information for participants included in the analysis.

\begin{tabular}{|c|c|c|c|c|c|}
\hline Group & Demographic items & $\begin{array}{l}\text { Survey } 1 \\
(\mathrm{n}=560)\end{array}$ & $\begin{array}{l}\text { Survey } 2 \\
(\mathrm{n}=678)\end{array}$ & $\begin{array}{l}\text { Survey 3 } \\
(\mathrm{n}=662)\end{array}$ & $\begin{array}{l}\text { Survey } 4 \\
(\mathrm{n}=513) \\
\end{array}$ \\
\hline \multirow{21}{*}{ Remain } & $n$ & 190 & 226 & 222 & 176 \\
\hline & Age range in years & $18-86$ & $18-87$ & $18-84$ & $19-85$ \\
\hline & Age Mean (SD) & $39.91(17.25)$ & $39.91(17.07)$ & $39.67(16.58)$ & $41.39(16.99)$ \\
\hline & Females & 120 & 145 & 148 & 110 \\
\hline & Recruit Type (n) & & & & \\
\hline & Volunteer / Student & 134 & 141 & 126 & 96 \\
\hline & Prolific & 30 & 59 & 73 & 58 \\
\hline & Older Adult Research Panel & 26 & 26 & 23 & 22 \\
\hline & Education Level (\%) & & & & \\
\hline & $\begin{array}{c}\text { School-level qualification (GCSE/A- } \\
\text { Level/ College Equivalent) }\end{array}$ & $15 \%$ & $8 \%$ & $18 \%$ & $15 \%$ \\
\hline & Undergraduate Degree & $44 \%$ & $9 \%$ & $44 \%$ & $44 \%$ \\
\hline & Post-graduate Degree & $42 \%$ & $5 \%$ & $38 \%$ & $41 \%$ \\
\hline & Prefer not to say / Did not answer & $0 \%$ & $1 \%$ & $0 \%$ & $0 \%$ \\
\hline & Missing & - & $77 \%$ & - & - \\
\hline & Political Affiliation (\%) $t$ & & & & \\
\hline & Right-wing & $11 \%$ & $4 \%$ & $14 \%$ & $13 \%$ \\
\hline & Left-wing & $42 \%$ & $10 \%$ & $37 \%$ & $50 \%$ \\
\hline & Centre & $12 \%$ & $2 \%$ & $14 \%$ & $11 \%$ \\
\hline & Other & $13 \%$ & $1 \%$ & $8 \%$ & $3 \%$ \\
\hline & Prefer not to say / None & $22 \%$ & $6 \%$ & $27 \%$ & $23 \%$ \\
\hline & Missing & $0 \%$ & $77 \%$ & $0 \%$ & $1 \%$ \\
\hline \multirow{21}{*}{ Leave } & $n$ & 153 & 214 & 212 & 174 \\
\hline & Age range in years & $18-82$ & $18-82$ & $18-82$ & $19-83$ \\
\hline & Age Mean (SD) & $41.24(14.95)$ & $42.94(14.28)$ & $43(13.84)$ & $44.36(13.08)$ \\
\hline & Females & 90 & 121 & 116 & 96 \\
\hline & Recruit Type (n) & & & & \\
\hline & Volunteer / Student & 16 & 23 & 22 & 14 \\
\hline & Prolific & 127 & 178 & 178 & 150 \\
\hline & Older Adult Research Panel & 10 & 13 & 12 & 10 \\
\hline & Education Level (\%) & & & & \\
\hline & $\begin{array}{c}\text { School-level qualification (GCSE/A- } \\
\text { Level/ College Equivalent) }\end{array}$ & $46 \%$ & $16 \%$ & $48 \%$ & $45 \%$ \\
\hline & Undergraduate Degree & $41 \%$ & $13 \%$ & $37 \%$ & $39 \%$ \\
\hline & Post-graduate Degree & $11 \%$ & $4 \%$ & $14 \%$ & $13 \%$ \\
\hline & Prefer not to say / Did not answer & $1 \%$ & $0 \%$ & $1 \%$ & $0 \%$ \\
\hline & Missing & $0 \%$ & $66 \%$ & $0 \%$ & $1 \%$ \\
\hline & Political Affiliation (\%) $t$ & & & & \\
\hline & Right-wing & $50 \%$ & $17 \%$ & $62 \%$ & $49 \%$ \\
\hline & Left-wing & $14 \%$ & $5 \%$ & $9 \%$ & $19 \%$ \\
\hline & Centre & $2 \%$ & $1 \%$ & $0 \%$ & $1 \%$ \\
\hline & Other & $2 \%$ & $0 \%$ & $4 \%$ & $3 \%$ \\
\hline & Prefer not to say / None & $32 \%$ & $10 \%$ & $24 \%$ & $28 \%$ \\
\hline & Missing & $0 \%$ & $67 \%$ & $1 \%$ & $0 \%$ \\
\hline \multirow{20}{*}{ US } & $n$ & 217 & 238 & 228 & 163 \\
\hline & Age range in years & $18-74$ & $18-75$ & $19-77$ & $19-77$ \\
\hline & Age Mean (SD) & $36.03(13.69)$ & $36.97(13.56)$ & $36.56(13.47)$ & $38.35(14.00)$ \\
\hline & Females & 91 & 105 & 114 & 81 \\
\hline & Recruit Type (n) & & & & \\
\hline & Volunteer / Student & 3 & 6 & 4 & 3 \\
\hline & Prolific & 214 & 232 & 224 & 160 \\
\hline & Education Level (\%) & & & & \\
\hline & $\begin{array}{c}\text { School-level qualification (GCSE/A- } \\
\text { Level/ College Equivalent) }\end{array}$ & $41 \%$ & $9 \%$ & $35 \%$ & $37 \%$ \\
\hline & Undergraduate Degree & $46 \%$ & $9 \%$ & $46 \%$ & $42 \%$ \\
\hline & Post-graduate Degree & $13 \%$ & $4 \%$ & $16 \%$ & $20 \%$ \\
\hline & Prefer not to say / Did not answer & $0 \%$ & $0 \%$ & $2 \%$ & $0 \%$ \\
\hline & Missing & $0 \%$ & $77 \%$ & $0 \%$ & $1 \%$ \\
\hline & Political Affiliation $(\%) \uparrow$ & & & & \\
\hline & Right-wing & $18 \%$ & $5 \%$ & $18 \%$ & $17 \%$ \\
\hline & Left-wing & $47 \%$ & $13 \%$ & $50 \%$ & $48 \%$ \\
\hline & Centre & $2 \%$ & $1 \%$ & $1 \%$ & $2 \%$ \\
\hline & Other & $13 \%$ & $1 \%$ & $9 \%$ & $7 \%$ \\
\hline & Prefer not to say / None & $20 \%$ & $4 \%$ & $22 \%$ & $25 \%$ \\
\hline & Missing & $0 \%$ & $77 \%$ & $0 \%$ & $1 \%$ \\
\hline
\end{tabular}


Table 2.

Survey Questions That are Relevant to the Current Analyses

\section{Memory Properties}

1) How vividly do you remember the time you became aware of the referendum outcome? (1. Not very 7 . Extremely)

2) What time was it when you found out the results?

3) How did you learn the outcome? [Multiple choice options: TV/ Internet/ Friends or Family/ Newspaper/ Radio / Other] Please use the box below to give us a little bit more detail about the source (such as the name of the TV programme you watched; the name of the website you checked).

4) Where were you when you found out the results? Please describe in one sentence and be specific.

5) Who else was there when you found out? Please describe in one sentence and be specific.

6) What were you doing beforehand?

7) What did you do immediately after finding out the results?

Follow-Up Surveys 2, 3 and 4 - Additional memory property questions.

8) How confident are you in your overall recollection of when you found out the referendum results? (1. Not at all -7.

Extremely)

\section{Voting Choice}

9) Were you eligible to vote in the 2016 UK's EU referendum?

10) How did you vote? [To remain in the EU/ To leave the EU/ I was eligible but did not vote]

\section{Emotional Intensity and Surprise}

Current feelings about the EU referendum result.

11) How strongly do you feel the following emotions when you think of the referendum now? (1. Not at all to 7 . Very strongly)
a. Angry
b. Proud
c. Sad
d. Happy
e. Anxious
f. Surprise

Personal Importance

12) How important are the referendum results to you? (1. Not important to 7. Extremely important)

\section{Rehearsal}

13) In the past week how closely have you followed the media coverage of the referendum result? [1. Rarely or none of the time or less than 1 day, 2. Some (1 - 2 days), 3. Occasionally (3 - 4 days), 4. Most of the time (5 - 6 days), 5. Daily]

14) Have you thought about the referendum since finding out the results? [1. Rarely or none of the time or less than 1 day, 2 . Some (1 - 2 days), 3. Occasionally (3 - 4 days), 4. Most of the time (5 - 6 days), 5. Daily]

15) Have you spent on the internet reading the latest news about the referendum? [1. Rarely or none of the time or less than 1 day, 2 . Some ( 1 - 2 days), 3. Occasionally (3 - 4 days), 4 . Most of the time (5 - 6 days), 5. Daily]

16) Have you talked about the referendum with your friends/family and colleagues? [1. Rarely or none of the time or less than 1 day, 2 . Some (1 - 2 days), 3. Occasionally (3 - 4 days), 4 . Most of the time (5 - 6 days), 5. Daily]

\section{Follow-Up Surveys - Additional rehearsal questions}

Survey 2

17) In the past 3 months.. Using the scale below, please select the most appropriate answer $(1=$ Very little to $7=A$ great deal $)$.

a. How closely have you followed the media coverage of the referendum result?

b. Have you thought about the referendum since finding out the results?

c. Have you spent on the internet reading the latest news about the referendum?

d. Have you talked about the referendum with your friends/family and colleagues?

Survey 3

18) In the past 9 months.. Using the scale below, please select the most appropriate answer $(1=$ Very little to $7=A$ great deal $)$.

a. How closely have you followed the media coverage of the referendum result?

b. Have you thought about the referendum since finding out the results?

c. Have you spent on the internet reading the latest news about the referendum?

d. Have you talked about the referendum with your friends/family and colleagues?

Survey 4

19) In the past 16 months.. Using the scale below, please select the most appropriate answer $(1=$ Very little to $7=A$ great deal $)$.

a. How closely have you followed the media coverage of the referendum result?

b. Have you thought about the referendum since finding out the results?

c. Have you spent on the internet reading the latest news about the referendum?

d. Have you talked about the referendum with your friends/family and colleagues?

\section{Demographics}

20) Please enter your age.

21) Where do you currently reside?

22) Please indicate your nationality.

23) Please indicate your gender/sex.

24) Please select your highest level of education.

25) What is your political affiliation? If other, please specify.

a. Conservative, b. Labour, c. Scottish National Party, d. Liberal Democrats, e. The UK Independence Party (UKIP), f. Republican (USA), g. Democrat (USA), h. None, i. Prefer not to say and j. Other 
Table 3.

Consistency, Confidence and Vividness in Flashbulb Memories and Negative Emotion,

Personal Importance, Surprise and Rehearsal as a Function of Voting Group and

Residency, Across All Surveys

Remain Leave US

\begin{tabular}{|c|c|c|c|c|c|c|}
\hline Memory assessments and survey & $M(\mathrm{SD})$ & $n$ & $M(\mathrm{SD})$ & $n$ & $M(\mathrm{SD})$ & $n$ \\
\hline \multicolumn{7}{|l|}{ Flashbulb Memory Consistency } \\
\hline 3 Months & $0.71(0.19)$ & 174 & $0.67(0.19)$ & 142 & $0.55(0.21)$ & 182 \\
\hline 9 Months & $0.68(0.19)$ & 140 & $0.63(0.21)$ & 98 & $0.56(0.23)$ & 144 \\
\hline 16 Months & $0.71(0.19)$ & 113 & $0.60(0.18)$ & 80 & $0.55(0.20)$ & 94 \\
\hline \multicolumn{7}{|l|}{ Flashbulb Memory Confidence } \\
\hline 3 Months & $5.91(1.04)$ & 226 & $5.75(1.30)$ & 214 & $4.37(1.65)$ & 238 \\
\hline 9 Months & $5.59(1.24)$ & 222 & $5.62(1.45)$ & 212 & $4.34(1.70)$ & 228 \\
\hline 16 Months & $5.40(1.26)$ & 176 & $5.52(1.43)$ & 174 & $3.96(1.75)$ & 163 \\
\hline \multicolumn{7}{|l|}{ Flashbulb Memory Vividness } \\
\hline 0 Months & $6.53(0.83)$ & 190 & $6.25(1.14)$ & 153 & $5.1(1.73)$ & 217 \\
\hline 3 Months & $6.21(1.06)$ & 226 & $6.01(1.37)$ & 214 & $4.13(1.84)$ & 238 \\
\hline 9 Months & $6.05(1.17)$ & 222 & $5.97(1.34)$ & 212 & $4.16(1.78)$ & 228 \\
\hline 16 Months & $5.77(1.38)$ & 176 & $5.58(1.70)$ & 174 & $3.65(1.70)$ & 163 \\
\hline \multicolumn{7}{|l|}{ Negative Emotion } \\
\hline 0 Months & $5.31(1.34)$ & 190 & $2.36(1.35)$ & 153 & $2.66(1.57)$ & 217 \\
\hline 3 Months & $5.00(1.51)$ & 226 & $2.08(1.29)$ & 214 & $2.23(1.37)$ & 238 \\
\hline 9 Months & $4.96(1.55)$ & 222 & $1.99(1.17)$ & 212 & $2.39(1.52)$ & 228 \\
\hline 16 Months & $4.89(1.63)$ & 176 & $2.24(1.30)$ & 174 & $2.18(1.43)$ & 163 \\
\hline \multicolumn{7}{|l|}{ Positive Emotion } \\
\hline 0 Months & $1.22(0.59)$ & 190 & $4.70(1.92)$ & 153 & $2.07(1.67)$ & 216 \\
\hline 3 Months & $1.33(0.72)$ & 226 & $4.69(1.97)$ & 214 & $1.83(1.47)$ & 238 \\
\hline 9 Months & $1.29(0.62)$ & 222 & $4.97(1.75)$ & 212 & $1.95(1.58)$ & 228 \\
\hline 16 Months & $1.30(0.72)$ & 176 & $4.47(1.91)$ & 174 & $1.77(1.46)$ & 163 \\
\hline \multicolumn{7}{|l|}{ Personal Importance } \\
\hline 0 Months & $6.41(0.78)$ & 189 & $5.83(1.31)$ & 153 & $3.81(1.64)$ & 217 \\
\hline 3 Months & $6.14(1.01)$ & 226 & $5.83(1.26)$ & 214 & $3.41(1.53)$ & 238 \\
\hline 9 Months & $5.99(1.15)$ & 222 & $5.93(1.22)$ & 212 & $3.51(1.62)$ & 228 \\
\hline 16 Months & $6.06(1.12)$ & 176 & $5.80(1.25)$ & 174 & $3.29(1.63)$ & 163 \\
\hline \multicolumn{7}{|l|}{ Surprise } \\
\hline 0 Months & $3.95(1.79)$ & 190 & $4.22(1.84)$ & 153 & $3.69(1.77)$ & 217 \\
\hline 3 Months & $3.77(1.82)$ & 226 & 3.73 (1.89) & 214 & $3.11(1.87)$ & 238 \\
\hline 9 Months & $3.53(1.67)$ & 222 & $3.83(1.78)$ & 212 & $3.14(1.92)$ & 228 \\
\hline 16 Months & $3.65(1.65)$ & 176 & $3.59(1.74)$ & 174 & $2.79(1.68)$ & 163 \\
\hline \multicolumn{7}{|l|}{ Rehearsal } \\
\hline 0 Months * & $4.25(0.86)$ & 190 & 3.55 (1.09) & 150 & $2.57(1.02)$ & 216 \\
\hline 3 Months & $4.83(1.42)$ & 226 & $4.41(1.61)$ & 214 & $2.69(1.46)$ & 238 \\
\hline 9 Months & $4.68(1.40)$ & 222 & $4.53(1.44)$ & 212 & $2.66(1.38)$ & 228 \\
\hline 16 Months & $4.37(1.43)$ & 176 & $4.15(1.45)$ & 174 & $2.36(1.30)$ & 163 \\
\hline
\end{tabular}

* Rehearsal measures were recorded on a 5 point Likert scale for Survey 1 and on a 7 point Likert scale for Surveys 2 (3 months), 3 (9 months) and 4 (16 months). 
Table 4.

Growth Curve Models of Negative and Positive Emotion

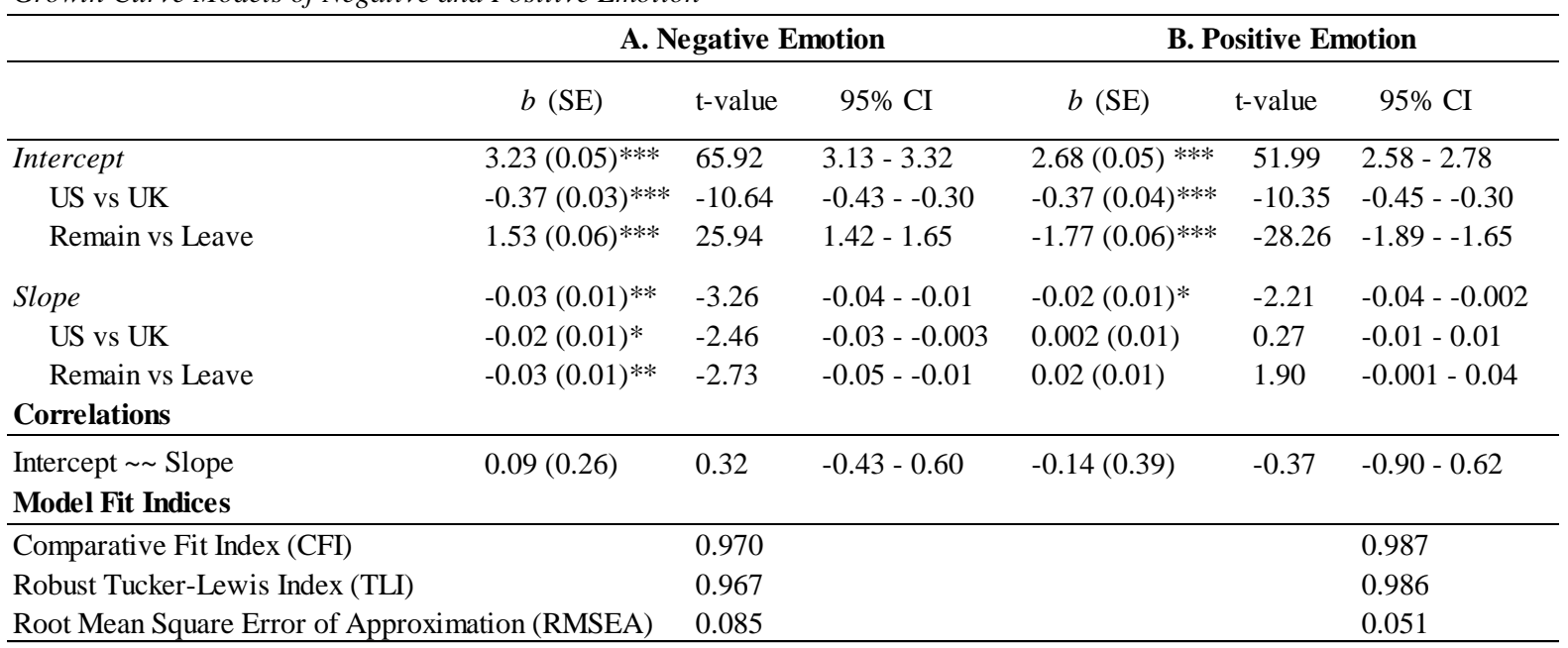

$* p<.05 . \quad * * p<.01 . \quad * * * p<.001$.

Table 5.

Growth Curve Models of (A) Memory Consistency, (B) Memory Confidence and (C) Memory Vividness

\begin{tabular}{|c|c|c|c|c|c|c|c|c|c|}
\hline & \multicolumn{3}{|c|}{ A. Memory Consistency } & \multicolumn{3}{|c|}{ B. Memory Confidence } & \multicolumn{3}{|c|}{ C. Memory Vividness } \\
\hline & $b$ (SE) & $\mathrm{t}$-value & $95 \% \mathrm{CI}$ & $b(\mathrm{SE})$ & $\mathrm{t}$-value & $95 \% \mathrm{CI}$ & $b$ (SE) & t-value & $95 \% \mathrm{CI}$ \\
\hline Intercept & $0.64(0.01) * * *$ & 63.35 & $0.62-0.66$ & $5.46(0.06) * * *$ & 96.94 & $5.35-5.57$ & $5.82(0.05) * * *$ & 115.27 & $5.73-5.92$ \\
\hline US vs UK & $-0.05(0.01)^{* * *}$ & -6.79 & $-0.06--0.04$ & $-0.48(0.04)^{* * *}$ & -11.03 & $-0.56--0.39$ & $-0.51(0.04) * * *$ & -13.10 & $-0.58--0.43$ \\
\hline Remain vs Leave & $0.01(0.01)$ & 0.86 & $-0.01-0.03$ & $0.12(0.06)$ & 1.90 & $-0.004-0.24$ & $0.10(0.05) *$ & 2.22 & $0.01-0.20$ \\
\hline Slope & $-0.003(0.002)$ & -1.48 & $-0.01-0.00$ & $-0.08(0.01)^{* * *}$ & -6.77 & $-0.11--0.06$ & $-0.14(0.01)^{* * *}$ & -12.35 & $-0.16--0.12$ \\
\hline US vs UK & $0.003(0.002)^{*}$ & 2.03 & $0.00-0.01$ & $0.001(0.01)$ & 0.10 & $-0.02-0.02$ & $-0.04(0.01) * * *$ & -4.39 & $-0.05--0.02$ \\
\hline Remain vs Leave & $0.01(0.002)^{*}$ & 2.36 & $0.00-0.01$ & $-0.03(0.01)^{*}$ & -2.14 & $-0.06--0.003$ & $-0.002(0.01)$ & -0.14 & $-0.03-0.02$ \\
\hline \multicolumn{10}{|l|}{ Correlations } \\
\hline Intercept Slope & $-0.40(0.17)^{*}$ & -2.38 & $-0.73--0.07$ & $0.27(0.21)$ & -1.29 & $-0.67-0.14$ & $0.31(0.30)$ & 1.03 & $-0.28-0.90$ \\
\hline \multicolumn{10}{|l|}{ Model Fit Indices } \\
\hline Comparative Fit Index (CFI) & & 0.988 & & - & 0.998 & & - & 0.939 & \\
\hline Robust Tucker-Lewis Index (TLI) & & 0.965 & & - & 0.995 & & - & 0.920 & \\
\hline Root Mean Square Error of Approx & mation (RMSEA) & 0.047 & & - & 0.021 & & - & 0.091 & \\
\hline
\end{tabular}

$* p<.05 . \quad * * p<.01 . \quad * * * p<.001$. 
Table 6.

Change of inconsistent flashbulb memories from Survey 2 to Survey 3 and from

Survey 3 to Survey 4.

\begin{tabular}{|llccc}
\hline \multirow{2}{*}{ Time } & & Corrected & Repeated & Changed \\
& Group & $M(\mathrm{SD})$ & $M(\mathrm{SD})$ & $M(\mathrm{SD})$ \\
\hline Survey 2 - 3 & Leave & $0.27(0.37)$ & $0.42(0.40)$ & $0.31(0.37)$ \\
$($ 3-9 months) & Remain & $0.30(0.36)$ & $0.41(0.39)$ & $0.29(0.36)$ \\
& US & $0.31(0.32)$ & $0.39(0.33)$ & $0.30(0.30)$ \\
\hline Survey 3 - 4 & Leave & $0.30(0.26)$ & $0.45(0.37)$ & $0.25(0.33)$ \\
$($ 9-16 months) & Remain & $0.33(0.38)$ & $0.40(0.41)$ & $0.27(0.38)$ \\
& US & $0.26(0.29)$ & $0.42(0.37)$ & $0.32(0.33)$ \\
\hline
\end{tabular}

Table 7.

Growth Curve Models of the Predictive Factors (A) Surprise, (B) Rehearsal and (C) Importance

\begin{tabular}{|c|c|c|c|c|c|c|c|c|c|}
\hline & \multicolumn{3}{|l|}{ A. Surprise } & \multicolumn{3}{|l|}{ B. Importance } & \multicolumn{3}{|l|}{ C. Rehearsal } \\
\hline & $b(\mathrm{SE})$ & t-value & $95 \% \mathrm{CI}$ & $b$ (SE) & t-value & $95 \% \mathrm{CI}$ & $b$ (SE) & t-value & $95 \% \mathrm{CI}$ \\
\hline Intercept & $3.80(0.06)^{* * *}$ & 58.64 & $3.68-3.93$ & $5.27(0.04)^{* * * *}$ & 118.45 & $5.18-5.36$ & $4.15(0.06)^{* * *}$ & 71.20 & $4.03-4.26$ \\
\hline US vs UK & $-0.14(0.04)^{* *}$ & -3.10 & $-0.22--0.05$ & $-0.8(0.03) * * *$ & -23.69 & $-0.87--0.74$ & $-0.67(0.04)^{* * *}$ & -16.70 & $-0.74--0.59$ \\
\hline Remain vs Leave & $-0.06(0.08)$ & -0.74 & $-0.22-0.1$ & $0.16(0.05)^{* * *}$ & 3.37 & $0.07-0.26$ & $0.19(0.07)^{* *}$ & 2.58 & $0.05-0.33$ \\
\hline Slope & $-0.09(0.01)^{* * *}$ & -7.02 & $-0.12--0.07$ & $-0.05(0.01) * * *$ & -5.75 & $-0.07--0.03$ & $-0.09(0.01)^{* * *}$ & -9.18 & $-0.11--0.07$ \\
\hline US vs UK & $-0.02(0.01)^{* *}$ & -2.57 & $-0.04--0.01$ & $-0.02(0.01) * * *$ & -2.45 & $-0.03--0.003$ & $0.003(0.01)$ & 0.42 & $-0.01-0.02$ \\
\hline Remain vs Leave & $0.01(0.02)$ & 0.35 & $-0.03-0.04$ & $-0.01(0.01)$ & -0.52 & $-0.02-0.01$ & $-0.01(0.01)$ & -0.90 & $-0.03-0.01$ \\
\hline \multicolumn{10}{|l|}{ Correlations } \\
\hline Intercept Slope & $-0.44-0.12$ & -3.80 & $-0.66--0.21$ & $-0.11(0.10)$ & -1.16 & $-0.30-0.08$ & $-0.33(0.15)^{*}$ & -2.14 & $-0.63--0.03$ \\
\hline \multicolumn{10}{|l|}{ Model Fit Indices } \\
\hline Comparative Fit Index (CFI) & - & 0.935 & & - & 0.982 & & - & 0.992 & \\
\hline Robust Tucker-Lewis Index (TLI) & - & 0.907 & & - & 0.978 & & - & 0.981 & \\
\hline Root Mean Square Error of Approximation (RMSEA) & - & 0.066 & & - & 0.061 & & - & 0.061 & \\
\hline
\end{tabular}

$* p<.05$. ** $p<.01$. *** $p<.001$ 
Table 8.

Predictive Factors as Mediators Between Residency and Voting Choice in (A) Memory Consistency, (B) Memory Confidence and (C) Memory Vividness

\begin{tabular}{|c|c|c|c|c|c|c|c|c|c|}
\hline & \multicolumn{3}{|c|}{ A. Memory Consistency } & \multicolumn{2}{|c|}{ B. Memory Confidence } & \multicolumn{4}{|c|}{ C. Memory Vividness } \\
\hline & $b$ (SE) & $\mathrm{t}$-value & $95 \% \mathrm{CI}$ & $b(\mathrm{SE})$ & t-value & $95 \% \mathrm{CI}$ & $b(\mathrm{SE})$ & t-value & $95 \% \mathrm{CI}$ \\
\hline \multicolumn{10}{|l|}{ Importance predicted by: } \\
\hline US vs UK & $-0.77(0.04)^{* * *}$ & -18.34 & $-0.85--0.69$ & $-0.77(0.04)^{* * *}$ & -18.63 & $-0.85--0.69$ & $-0.77(0.04)^{* * *}$ & -18.70 & $-0.85--0.69$ \\
\hline Remain vs Leave & $0.29(0.06)^{* * *}$ & 4.84 & $0.17-0.41$ & $0.29(0.06)^{* * *}$ & 4.90 & $0.17-0.40$ & $0.28(0.06)^{* * *}$ & 4.68 & $0.16-0.39$ \\
\hline \multicolumn{10}{|l|}{ Negative emotion predicted by: } \\
\hline US vs UK & $-0.39(0.04)^{* * * *}$ & -9.12 & $-0.48--0.31$ & $-0.39(0.04)^{* * * *}$ & -9.18 & $-0.48--0.31$ & $-0.39(0.04) * * *$ & -9.14 & $-0.48--0.31$ \\
\hline Remain vs Leave & $1.47(0.07)^{* * * *}$ & 20.19 & $1.33-1.62$ & $1.47(0.07)^{* * *}$ & 20.10 & $1.32-1.61$ & $1.46(0.07)^{* * *}$ & 19.97 & $1.32-1.61$ \\
\hline \multicolumn{10}{|l|}{ Positive emotion predicted by: } \\
\hline US vs UK & $-0.30(0.04)^{* * *}$ & -6.38 & $-0.39--0.20$ & $-0.30(0.05)^{* * *}$ & -6.44 & $-0.39--0.21$ & $-0.30(0.05)^{* * *}$ & -6.44 & $-0.39--0.21$ \\
\hline Remain vs Leave & $-1.74(0.08)^{* * *}$ & -21.73 & $-1.90--1.59$ & $-1.75(0.08)^{* * *}$ & -22.13 & $-1.9--1.59$ & $-1.76(0.08)^{* * *}$ & -22.13 & $-1.91--1.60$ \\
\hline \multicolumn{10}{|l|}{ Rehearsal predicted by: } \\
\hline US vs UK & $-0.44(0.03)^{* * *}$ & -14.99 & $-0.50--0.38$ & $-0.44(0.03)^{* * *}$ & -15.23 & $-0.5--0.38$ & $-0.44(0.03)^{* * *}$ & -15.57 & $-0.50--0.39$ \\
\hline Remain vs Leave & $0.35(0.05)^{* * *}$ & 6.54 & $0.25-0.46$ & $0.35(0.05)^{* * *}$ & 6.56 & $0.25-0.45$ & $0.34(0.05)^{* * *}$ & 6.33 & $0.23-0.44$ \\
\hline \multicolumn{10}{|l|}{ Surprise predicted by: } \\
\hline US vs UK & $-0.13(0.05)^{* *}$ & -2.56 & $-0.23--0.03$ & $-0.13(0.05)^{* *}$ & -2.54 & $-0.23--0.03$ & $-0.13(0.05)^{* *}$ & -2.56 & $-0.23--0.03$ \\
\hline Remain vs Leave & $-0.13(0.10)$ & -1.34 & $-0.32-0.06$ & $-0.14(0.10)$ & -1.37 & $-0.33-0.06$ & $-0.14(0.10)$ & -1.46 & $-0.34-0.05$ \\
\hline \multicolumn{10}{|l|}{ Intercept predicted by: } \\
\hline Importance & $0.01(0.01)$ & 1.09 & $-0.01-0.03$ & $0.25(0.06)^{* * *}$ & 3.86 & $0.12-0.37$ & $0.19(0.05)^{* * *}$ & 3.55 & $0.09-0.30$ \\
\hline Negative Emotion & $0.002(0.01)$ & 0.28 & $-0.01-0.02$ & $-0.05(0.05)$ & -0.85 & $-0.15-0.06$ & $0.05(0.04)$ & 1.32 & $-0.03-0.13$ \\
\hline Positive Emotion & $-0.02(0.01)^{*}$ & -2.38 & $-0.03--0.003$ & $0.05(0.05)$ & 1.02 & $-0.05-0.15$ & $0.09(0.04)^{*}$ & 2.11 & $0.01-0.16$ \\
\hline Rehearsal & $-0.01(0.01)$ & -0.76 & $-0.03-0.01$ & $0.28(0.08)^{* * *}$ & 3.53 & $0.12-0.43$ & $0.37(0.05)^{* * *}$ & 7.63 & $0.28-0.47$ \\
\hline Surprise & $0.001(0.01)$ & 0.18 & $-0.01-0.01$ & $0.05(0.04)$ & 1.28 & $-0.03-0.12$ & $0.05(0.03)$ & 1.84 & $-0.003-0.10$ \\
\hline US vs UK & $-0.05(0.01)^{* * * *}$ & -5.03 & $-0.07--0.03$ & $-0.17(0.06)^{* *}$ & -2.63 & $-0.29--0.04$ & $-0.14(0.05)^{* *}$ & -2.90 & $-0.24--0.05$ \\
\hline Remain vs Leave & $-0.03(0.02)$ & -1.35 & $-0.06-0.01$ & $0.11(0.12)$ & 0.98 & $-0.12-0.35$ & $0.003(0.09)$ & 0.04 & $-0.17-0.17$ \\
\hline \multicolumn{10}{|l|}{ Slope predicted by: } \\
\hline Importance & $-0.004(0.002)$ & -1.83 & $-0.01-0.00$ & $-0.03(0.02)$ & -1.43 & $-0.06-0.01$ & $-0.03(0.01)^{*}$ & -2.20 & $-0.05--0.003$ \\
\hline Negative Emotion & $-0.002(0.002)$ & -1.25 & $-0.01-0.001$ & $0.02(0.01)$ & 1.41 & $-0.01-0.05$ & $0.01(0.01)$ & -0.001 & $-0.02-0.02$ \\
\hline Positive Emotion & $0.001(0.002)$ & 0.65 & $-0.002-0.004$ & $0.02(0.01)$ & 1.14 & $-0.01-0.04$ & $0.01(0.01)$ & 0.93 & $-0.01-0.03$ \\
\hline Rehearsal & $0.01(0.002)^{*}$ & 2.31 & $0.001-0.01$ & $-0.02(0.02)$ & -0.81 & $-0.06-0.02$ & $0.01(0.01)$ & 0.58 & $-0.02-0.04$ \\
\hline Surprise & $0.001(0.001)$ & -0.01 & $-0.002-0.002$ & $-0.01(0.01)$ & -0.61 & $-0.03-0.01$ & $-0.004(0.01)$ & -0.53 & $-0.02-0.01$ \\
\hline US vs UK & $0.002(0.002)$ & 0.99 & $-0.002-0.01$ & $-0.01(0.01)$ & -1.01 & $-0.04-0.01$ & $-0.05(0.01)^{* * *}$ & -4.42 & $-0.07--0.03$ \\
\hline Remain vs Leave & $0.01(0.004)^{* *}$ & 2.53 & $0.002-0.02$ & $-0.02(0.03)$ & -0.69 & $-0.08-0.04$ & $0.02(0.02)$ & 1.00 & $-0.02-0.06$ \\
\hline \multicolumn{10}{|l|}{ Model Fit Indices } \\
\hline Comparative Fit Index (CFI) & - & 0.995 & & - & 0.999 & & - & 0.976 & \\
\hline Robust Tucker-Lewis Index (TLI) & - & 0.977 & & - & 0.996 & & - & 0.934 & \\
\hline Root Mean Square Error of Approximation (RMSEA) & - & 0.043 & & - & 0.016 & & - & 0.063 & \\
\hline
\end{tabular}

$* p<.05 . \quad * * p<.01 . \quad * * * p<.001$. 


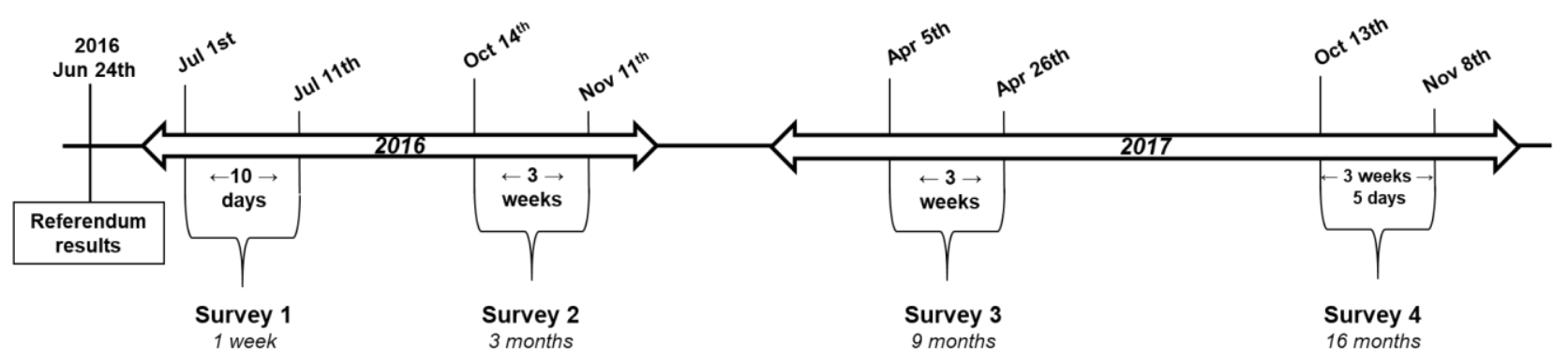

Figure 1. Timeline of survey administration including start and end dates and duration for each survey.

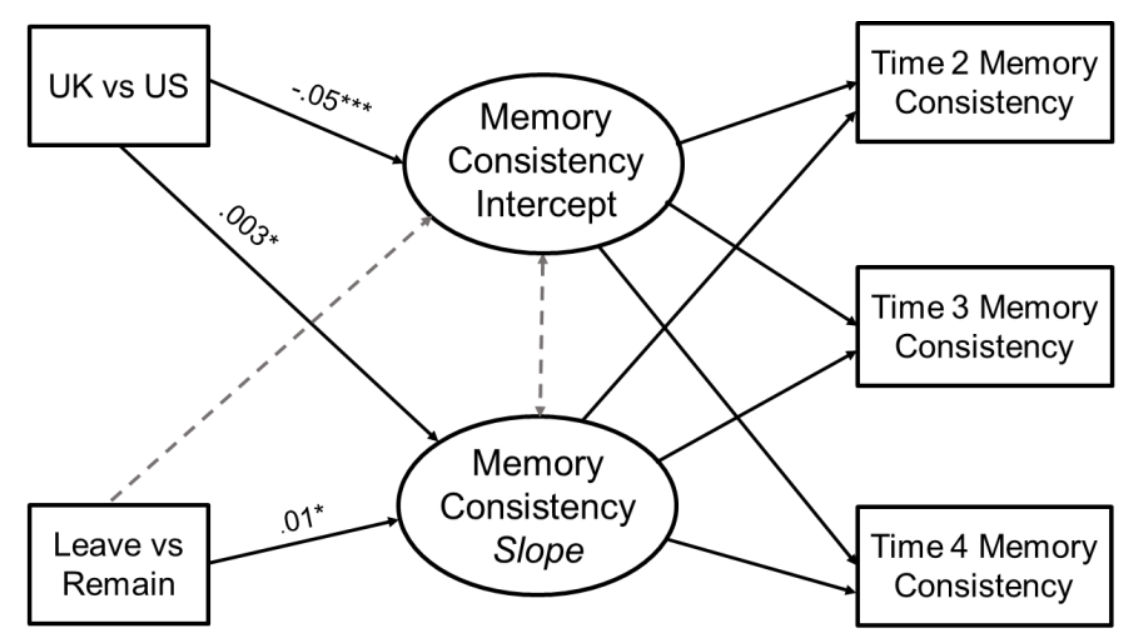

Figure 2. Path diagram for memory consistency. The two group variables used orthogonal contrast coding: UK vs US (UK $=-1 ;$ US $=2$ ) and Leave vs Remain (Leave $=-1 ;$ Remain $=1)$. Dashed grey lines were nonsignificant paths. 
A

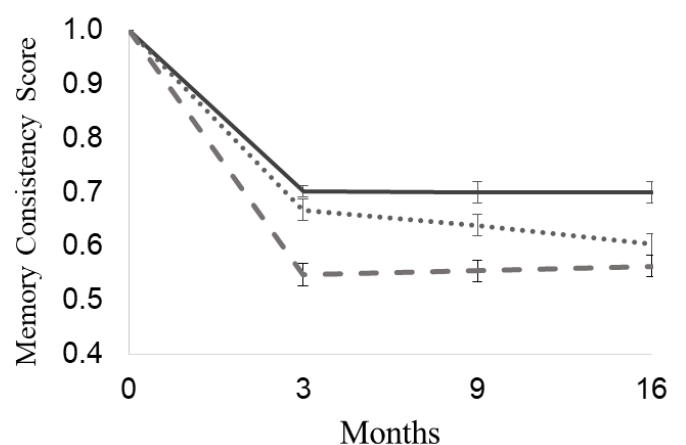

B

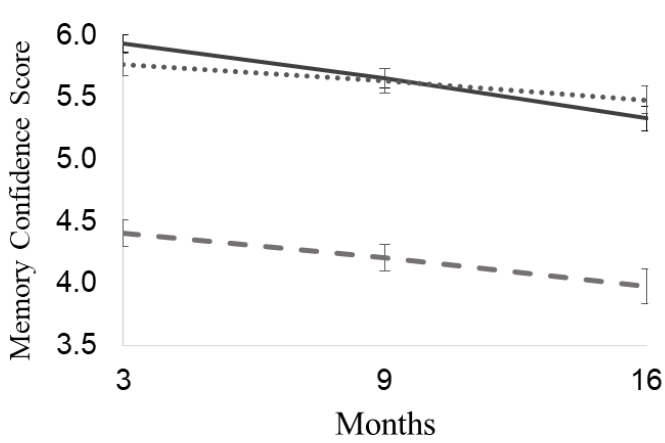

C

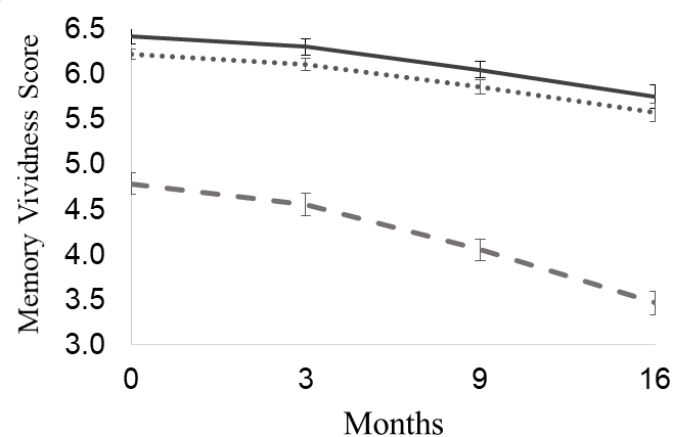

Figure 3. Mean ratings for Remain and Leave voters and US participants for (A) memory consistency, (B) memory confidence and (C) memory vividness. Error bars represent standard errors of means.

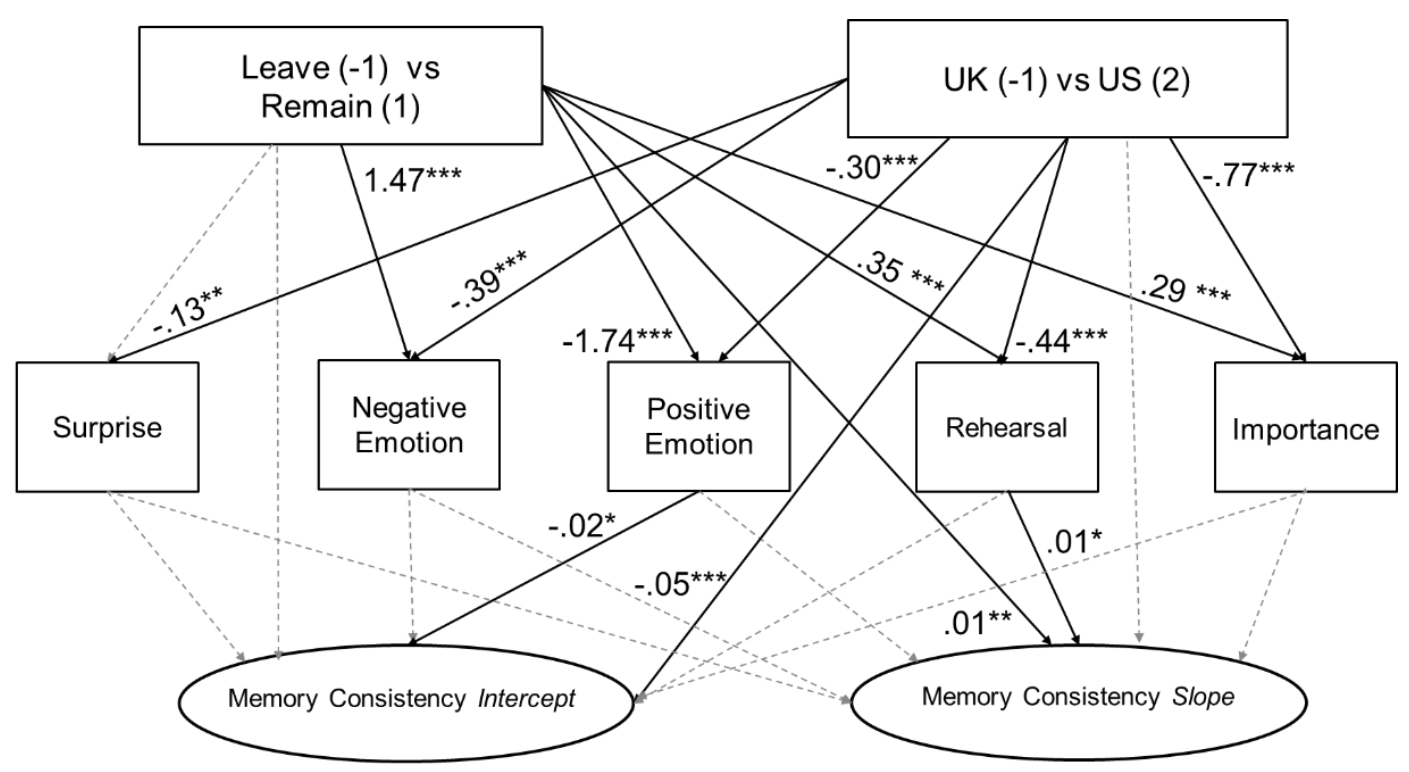

Figure 4. Path diagram of the mediation model for memory consistency. The two group variables used orthogonal contrast coding: UK vs US (UK = -1; US = 2) and Leave vs Remain (Leave = -1; Remain =1). Dashed grey lines were nonsignificant paths. 


\section{Memory of the UK's 2016 EU Referendum: The effects of valence on the long- term measures of a public event.}

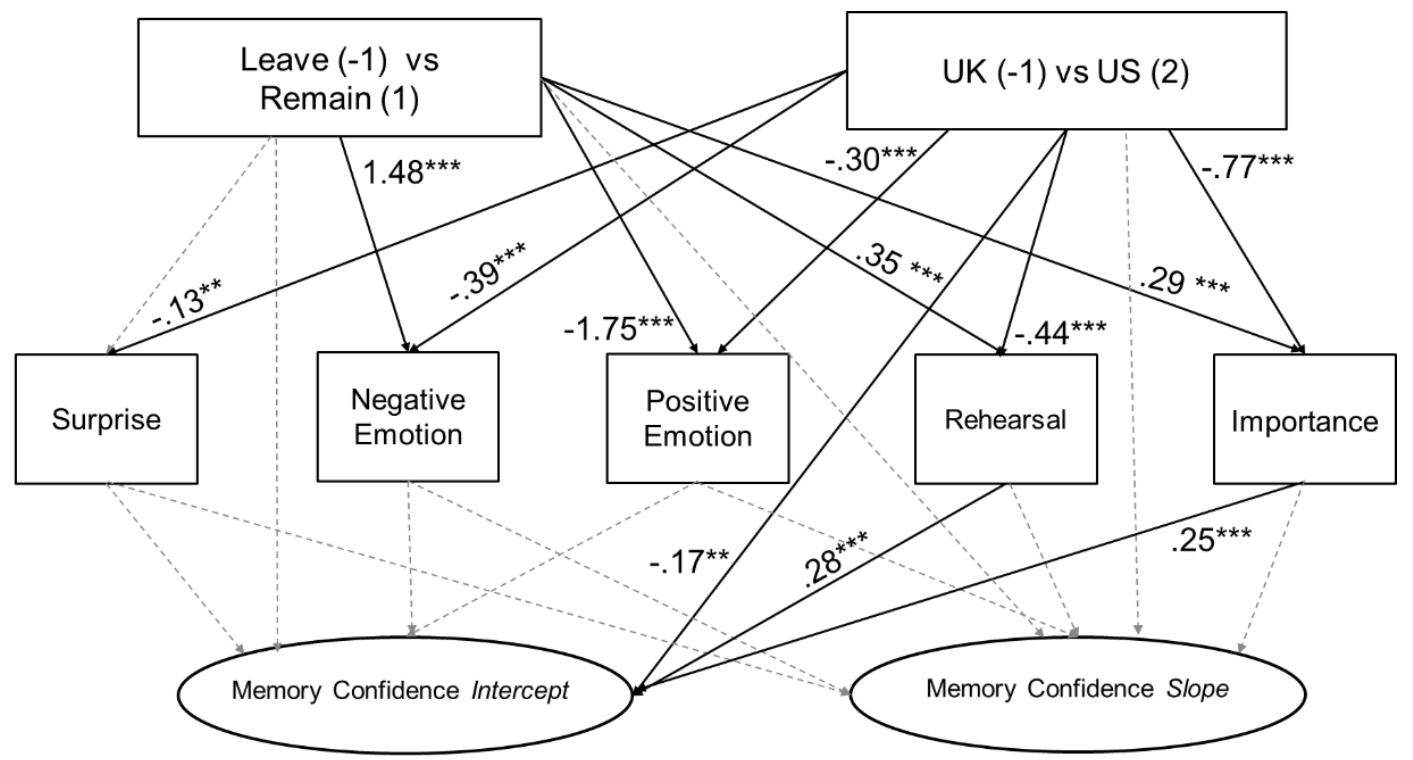

Figure 5. Path diagram of the mediation model for memory confidence. The two group variables used orthogonal contrast coding: UK vs US (UK = -1 ; US = 2) and Leave vs Remain (Leave = -1 ; Remain =1). Dashed grey lines were nonsignificant paths.

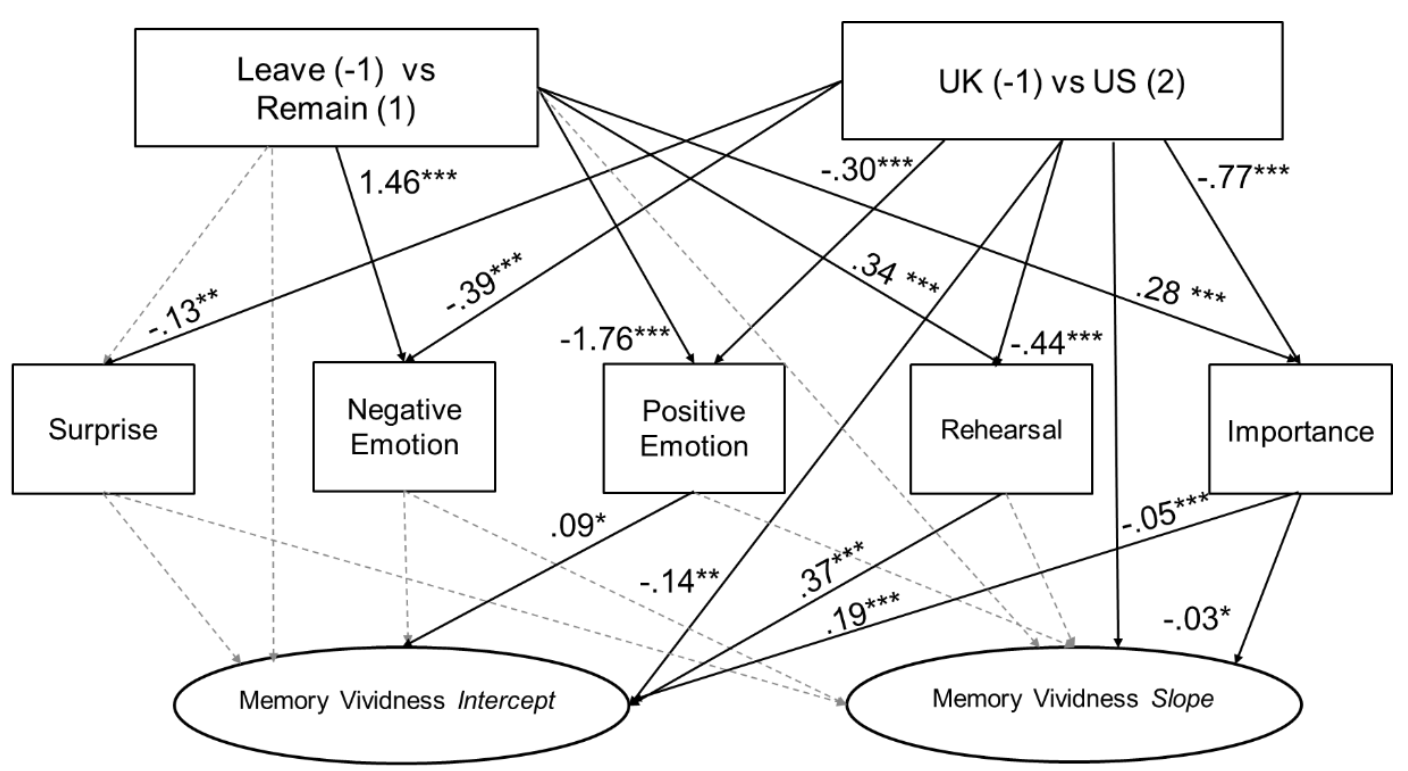

Figure 6. Path diagram of the mediation model for memory vividness. The two group variables used orthogonal contrast coding: UK vs US (UK $=-1$; US $=2$ ) and Leave vs Remain (Leave $=-1$; Remain $=1$ ). Dashed grey lines were nonsignificant paths. 


\section{Memory of the UK's 2016 EU Referendum: The effects of valence on the long- term measures of a public event.}

\section{Supplemental Materials}

\section{Details of Coding}

What time was it when you found out the results? For the question "what time was it when you found out the results?" we coded the data in two ways. The first method of coding, the "specific or average" coding column recorded the participant's response into a 24-hour format e.g. if the response was "7:30am", then it would be coded as "07:30". The second method, the "specific or approximate" coding, translated time entries (numerical or descriptive) that either reflected very precise times (e.g. "7:22am") or more vague times (e.g. "In the morning") into a time category. Since not all responses were written in a time format and often included more descriptive responses such as "Morning", we used the data from this method of coding to create the memory consistency score.

How did you learn the outcome? For the question "how did you learn the outcome?" participants were given pre-defined options to choose from (e.g. television, internet, friends and family, newspaper, radio and other). The pre-defined options were then translated into coding categories (e.g. 0-6) which were then compared across time points.

Where were you when you found out the results? For the question "where were you when you found out the results?" we coded the data in three separate ways to record the geographic locations of participants. The first method of coding recorded the actual site i.e. if they were at home, at work or school, or if they were commuting etc. For example, if the participant responded "I was at home watching TV", it would have been recorded as 'home'. The second method of coding recorded participant's 'geographic site' e.g. if they responded "In London, UK," while the third method of coding recorded the room location e.g. "I was in my bedroom". Since most responses did not include highly specific and/or detailed locations mentioning geographic locations and/or specific rooms, we used the 'actual site' coded data for our memory consistency score. 


\section{Memory of the UK's 2016 EU Referendum: The effects of valence on the long- term measures of a public event.}

Who else was there when you found out? For the question "who else was there when you found out the results?' we coded each person category (e.g. 'spouse/lover', 'parent', 'child" etc.) as " 1 " if they were mentioned or " 0 " if they were not mentioned.

What were you doing beforehand? For the question "what were you doing beforehand?" we converted each response into a behavior category (e.g. 'awaking', 'preparing for the day', 'commuting', 'leisure activities' etc.).

What did you do immediately after finding out the results? For the question "what did you do immediately after finding out the results?" we used our primary coding score to code the initial behavior stated rather than our secondary and additional coding scores which reflected secondary and additional behaviors. Like the previous question, we converted each response into a behavior category (e.g. 'emoted', 'followed the news, 'communicated', 'preparing for the day' etc.) and then compared these across time points.

\section{Supplemental Results}

\section{Differences in Demographic Characteristics across the Three Groups}

In order to examine whether there were any group differences on measures of age, sex and level of education, three separate one-way ANOVAs were carried out for each time point using RStudio (v. 1.1.463) and the stats (v. 3.6.2) package (R Core Team, 2019).

Age. The age of participants was significantly different between groups at each survey ( $p$ s <.005). Post-hoc analysis using Bonferroni multiple comparison test revealed that across all surveys, US participants were significantly younger than Leave participants, $p=.004 p$ $<.001 ; p<.001 ; p<.001$ (Surveys $1-4$ respectively). There were no significant differences between Leave and Remain participants ( $p \mathrm{~s}>.05$ ) or between US and Remain participants ( $p \mathrm{~s}$ $>.05)$.

Gender. The gender distribution for each group across Surveys 1, 2 and 3 was significantly different ( $p$ s <.05). In Surveys 1, 2 and 3, the Remain group had significantly 


\section{Memory of the UK's 2016 EU Referendum: The effects of valence on the long- term measures of a public event.}

more female participants: $z=3.20, p=.008 ; z=3.50, p=.003$ and $z=3.53, p=.002$ (Surveys 1-3 respectively) whereas US participants had significantly more males, $z=4.46, p<.001 ; z=$ $4.17, p<.001$ and $z=2.68, p=.045$ (Surveys $1-3$ respectively).

Education. The level of education among participants was significantly different between groups at Survey 1,3 and $4(p s<.001)$ but not Survey $2 .{ }^{6}$ Post-hoc analysis using Bonferroni's multiple comparison test revealed that at Surveys 1, 3 and 4, Remain participants had significantly higher levels of education compared to both Leave and US participants ( $p$ s < .001). In addition, at Survey 3, US participants had higher levels of education than Leave participants, $p=.017$

\section{Effects of Residency and Voting Choice on Memory}

Since our groups differed significantly on measures of age, education level and gender, we re-ran the SEM models (see S-Table 2) to ensure that our results were not being driven by group differences in these measures.

Memory consistency. The analysis on memory consistency supported our initial findings in that UK participants had a higher memory consistency score for Survey $2, \beta=-$ $.05, t=-6.79, p<.001$, even after controlling for gender, age and education, $\beta=-.05, t=-$ $6.16, p<.001$ (S-Table 2A). Likewise, Leave and Remain participants did not significantly differ in their initial memory consistency level at Survey $2(p=.69)$, but significantly differed in the slope, $\beta=.01, t=1.99, p=.046$, suggesting that once again, Leave participants exhibited a quicker rate of decline in memory consistency. These results support our initial findings even after controlling for age, gender and education level. However, one difference between the current results and our initial findings is that after controlling for age, gender and

\footnotetext{
${ }^{6}$ Due to a technical error in Survey 2, we do not have education level information for $67 \%$ Leave participants, $79 \%$ for Remain participants and $77 \%$ for US participants. This could therefore explain the non-significant findings.
} 


\section{Memory of the UK's 2016 EU Referendum: The effects of valence on the long- term measures of a public event.}

education, we no longer find a significant difference in the slope between UK and US residents.

Memory confidence. A similar analysis on memory confidence (S-Table 2B) also confirmed our previous findings. Once again, initial confidence levels at Survey 2 (as reflected by the intercepts) were higher for UK participants compared to US participants, $\beta=$ $-.47, t=-10.13, p<.001$. Furthermore, there were no significant differences between the US and UK participants in their slopes $(p=.46)$ but there was a significant effect of voting choice, $\beta=-.05, t=-3.34, p=.001$, suggesting that Remain participants exhibited a quicker rate of decline in memory confidence compared to Leave participants. In addition, the two voting groups were not significantly different in the initial levels of confidence $(p=.05)$. Like memory consistency, these results for memory confidence offer further support to our initial findings, even after controlling for age, gender and education.

Memory vividness. A similar analysis on memory vividness (S-Table 2C) partially confirmed our initial results. Like before, the results revealed that UK participants, compared to US participants, had higher intercepts for their memory vividness, $\beta=-.50, t=-12.36, p<$ .001 , with a smaller decline over time, $\beta=-.03, t=-3.84, p<.001$. We also confirmed that Leave and Remain participants exhibited a similar level of decline over time $(p=.60)$. However, unlike our previous findings, after controlling for age, gender and education level, we no longer found a significant difference in the intercept for memory vividness between Leave and Remain participants, $\beta=.07, t=1.29, p=.20$. Thus, it seems that after controlling for age, gender and education level, Remain and Leave voters recall memories that are equally as vivid, both initially and across a period of 16 months.

\section{Mediation Analysis Including Age, Education and Gender as Covariates}

We also re-ran the mediation models while including these demographic variables as covariates (see S-Table 3). Across all three mediation models, after controlling for age, 


\section{Memory of the UK's 2016 EU Referendum: The effects of valence on the long- term measures of a public event.}

education level and gender, we replicated our initial findings for memory consistency (STable 3A), memory confidence (S-Table 3B) and memory vividness (S-Table 3C), suggesting that the effects of group were not being driven by the significant differences in the demographic variables.

\section{Recoded Memory Consistency}

A second memory consistency score was obtained, this time using a combination of the Hirst et al. (2009) and the Neisser and Harsch (1992) coding scheme. Here, we focused on responses that had originally received a " 0 " for the initial consistency score but this time allowed memories that were less specific and/or with more/less detail than previously documented, to be considered consistent. In other words, if the responses were initially deemed inconsistent but matched the gist of the initial memory, with more or less detail than before, they were now assigned a " 1 " to reflect consistency. On the other hand, if they were completely different, absent or did not answer the question, the response received a "0". Responses that were initially consistent maintained a "1". Thus, a secondary consistency score, more similar to that of Neisser and Harsch (1992), was created. Similar to the memory consistency score reported in the main text, the recoded memory consistency score was the averaged memory consistency of the 6 recoded questions (Table 2, Questions 2-7) and ranged from 0 to 1 .

Another SEM model was carried out with the recoded memory consistency score as the dependent variable (see S-Table 4). Once again, effect coding was used to create two group variables; one to compare UK participants (Leave and Remain voters) with US participants (referred to as $U K v s U S$ in the model) and the second to compare Remain voters with Leave voters (referred to as $R v s L$ in the model). The analysis revealed that, like before, UK participants had a higher memory consistency score for Survey $2, \beta=-.04, t=-6.38, p$ $<.001$, but this time, did not have a steeper decline when compared to US participants, $p=$ 


\section{Memory of the UK's 2016 EU Referendum: The effects of valence on the long- term measures of a public event.}

.097 (S-Table 4). More importantly, we again found that while Leave and Remain voters were not significantly different in their initial memory consistency level at Survey $2(p=.25)$, they did significantly differ in the slope; Leave participants exhibited a quicker rate of decline in memory consistency, $\beta=.01, t=2.61, p=.009$ (see S-Table 4). These results suggest that the effects of valence we found in our main analyses are not due to the way we coded our memory data.

\section{Memory for Emotional Reactions}

Since previous research has suggested that memories for emotional responses tend to be less accurate than memories for other aspects (Hirst et al., 2009), we also asked participants about their memory of their emotional reactions (emotional intensity and surprise) from when they found the results of the referendum (S-Table 5 Questions 1a-1f; angry, sad, anxious, happy, proud and surprise all with 7-point Likert scales). We created two measures of emotion for each time point; one to reflect memory of negative emotion and another to reflect memory of positive emotion and separately used measures of surprise.

We then explored the effects of voting choice and residency on memory for initial emotional reactions; thus three SEM analyses (similar to the one used for current levels of positive and negative emotion) were performed separately on participants' memory for how negatively or positively they felt and how surprised they felt after learning the referendum results.

As is evident in S-Tables 7A-B, Remain participants had higher intercepts for memory of negative emotion compared to Leave participants, $\beta=1.84, t=37.61, p<.001$ but lower intercepts for memory of positive emotion, $\beta=-2.04, t=37.01, p<.001$. UK participants, compared to US participants, had higher intercepts of both negative emotion, $\beta=$ $-0.34, t=-9.96, p<.001$ and positive emotion, $\beta=-0.38, t=-10.75, p<.001$. While all groups seemed to forget their initial levels of positive and negative emotion over time, there 


\section{Memory of the UK's 2016 EU Referendum: The effects of valence on the long- term measures of a public event.}

were no significant differences in the how quickly they forgot negative (UK vs US, $p=.25$; Leave vs Remain, $p=.17$ ) or positive emotion (UK vs US, $p=.57$; Leave vs Remain, $p=$ .62). Together, these results suggest that memory for the intensity of positive and negative affect, at the time of learning the referendum results, was forgotten at a similar rate for all participants, irrespective of voting choice or residency.

As for participants' memory for how surprised they were, UK and US participants recalled feeling just as surprised $(p=.086)$ but Remain participants recalled feeling more surprised than Leave voters, $\beta=.21, t=2.97, p=.003$ (see S-Table 7C). Unlike the results for memory of negative and positive emotion where all groups showed a similar rate of decline over time, the results for memory of surprise suggests that US participants forgot their initial levels of surprise more quickly over time compared to UK participants, $\beta=-.02, t=-2.51, p=$ .012. However, there were no differences in the rate of change over time between the two UK voting groups $(p=.87)$ suggesting that they forgot their initial levels of surprise at a similar rate.

Previous research has argued that emotional reactions are forgotten more quickly than levels of consistency, confidence and vividness (Hirst et al., 2009, 2015). Past research has also shown that memories for emotional reactions can be influenced by our current emotional state (Levine et al., 2001, 2005) and that post-event information can encourage us to underor over-estimate our past emotions (Safer et al., 2002). Consistent with these prior findings, we found that participants' memory for their initial reaction of surprise declined over time for all groups of participants but especially for US participants. These findings fit with the idea that individuals use their current emotional states when remembering past emotional experiences (Levine \& Safer, 2002). In other words, they are more likely to recall past emotions that are more consistent with their current feelings. In contrast, we did not find a significant effect of time for how negative or positive participants originally felt, indicating 


\section{Memory of the UK's 2016 EU Referendum: The effects of valence on the long- term measures of a public event.}

that all groups forgot their initial emotional reactions at a similar rate over time. Interestingly, when we analyzed their current levels of negative and positive emotion, these emotions declined with time suggesting that memory for them does not seem to be biased by current feelings. Although this finding is contrary to previous research which has found that past emotions are often over- or under-estimated depending on the current appraisal of the event (Levine et al., 2001; Safer et al., 2002) or that they are forgotten more quickly than other features of a flashbulb memory (Hirst et al., 2009), it could be that we have not yet seen evidence of this bias and/or effect within our timeframe of 16 months, especially as there was also no official outcome of the referendum vote within this time. Once again, these results may be specific to this particular event and as such, future research should further investigate the consistency of memory for past emotional reactions.

\section{Perception of change to life}

In Surveys 2 we asked "Since the referendum results, has your life got better, got worse or stayed the same?" and participants were asked to choose one of the three options (a) "got better", (b) "got worse" or (c) "stayed the same”. A chi-square test of independence was performed to examine the relationship between group (Remain vs. Leave participants) and the perception of change to life (changed: better or worse vs. stayed the same) ${ }^{7}$. We found that the two groups significantly differed in their perception of change to their lives since the referendum results, $\chi 2(1)=11.09, p<.001$. In Survey $2,21 \%$ of Remain participants said that their life had changed (got better or worse) compared to only $8 \%$ of Leave participants. These results suggest that participants may have differed in their perception of how much the EU referendum results changed their lives.

\footnotetext{
7 The cell sizes for "got better" and "got worse" were smaller than 5, therefore we combined these two measures into one variable to represent "change".
} 
Memory of the UK's 2016 EU Referendum: The effects of valence on the longterm measures of a public event.

S Table 1

Correlations of predictive factors in Survey 1

\begin{tabular}{lccccc}
\hline & $\mathbf{1}$ & $\mathbf{2}$ & $\mathbf{3}$ & $\mathbf{4}$ & $\mathbf{5}$ \\
\hline 1. Rehearsal & - & & & & \\
2. Personal Importance & $0.67^{* * *}$ & - & & & \\
3. Positive Emotion & 0.03 & $0.20^{* * *}$ & - & & \\
4. Negative Emotion & $0.47^{* * *}$ & $0.44^{* * *}$ & $-0.47 * * *$ & - & \\
5. Surprise & $0.22^{* * *}$ & $0.21^{* * *}$ & $0.14 * *$ & $0.21 * * *$ & - \\
\hline
\end{tabular}


Memory of the UK's 2016 EU Referendum: The effects of valence on the long-term measures of a public event.

S Table 2

Growth Curve Models of (A) Memory Consistency, (B) Memory Confidence and (C) Memory Vividness After Controlling for Age, Education and Gender.

\begin{tabular}{|c|c|c|c|c|c|c|c|c|c|}
\hline & \multicolumn{3}{|c|}{ A. Memory Consistency } & \multicolumn{3}{|c|}{ B. Memory Confidence } & \multicolumn{2}{|c|}{ C. Memory Vividness } & \multirow[b]{2}{*}{$95 \% \mathrm{CI}$} \\
\hline & $b(\mathrm{SE})$ & t-value & $95 \% \mathrm{CI}$ & $b(\mathrm{SE})$ & $\mathrm{t}$-value & $95 \% \mathrm{CI}$ & $b(\mathrm{SE})$ & $\mathrm{t}$-value & \\
\hline Intercept & $0.56(0.06)^{* * *}$ & 9.76 & $0.45-0.67$ & $5.38(0.36)^{* * *}$ & 15.02 & $4.68-6.08$ & $5.55(0.29)^{* * *}$ & 19.41 & $4.99-6.11$ \\
\hline US vs UK & $-0.05(0.01)^{* * * *}$ & -6.16 & $-0.06--0.03$ & $-0.47(0.05)^{* * *}$ & -10.13 & $-0.57--0.38$ & $-0.5(0.04)^{* * *}$ & -12.36 & $-0.58--0.42$ \\
\hline Remain vs Leave & $0.01(0.01)$ & 0.39 & $-0.02-0.03$ & $0.14(0.07)^{*}$ & 1.96 & $0.00-0.28$ & $0.07(0.05)$ & 1.29 & $-0.04-0.18$ \\
\hline Age & $0.002(0.01)$ & 0.26 & $-0.01-0.02$ & $0.01(0.004)$ & 1.83 & $-0.001-0.02$ & $0.002(0.003)$ & 0.63 & $-0.004-0.01$ \\
\hline Education & $0.01(0.01)$ & 0.87 & $-0.01-0.03$ & $-0.03(0.07)$ & -0.38 & $-0.16-0.11$ & $0.08(0.06)$ & 1.44 & $-0.03-0.19$ \\
\hline Gender & $0.03(0.02)$ & 1.26 & $-0.02-0.07$ & $-0.08(0.14)$ & -0.55 & $-0.36-0.20$ & $-0.07(0.11)$ & -0.62 & $-0.28-0.15$ \\
\hline Slope & $0.002(0.01)$ & 0.15 & $-0.02-0.03$ & $-0.32(0.08)^{* * *}$ & -3.89 & $-0.48--0.16$ & $-0.22(0.08) * *$ & -2.89 & $-0.37--0.07$ \\
\hline US vs UK & $0.003(0.002)$ & 1.83 & $0.00-0.01$ & $0.01(0.01)$ & 0.74 & $-0.01-0.03$ & $-0.03(0.01)^{* * * *}$ & -3.84 & $-0.05--0.02$ \\
\hline Remain vs Leave & $0.01(0.003)^{*}$ & 2.00 & $0.00-0.01$ & $-0.05(0.02)^{* * *}$ & -3.34 & $-0.08--0.02$ & $-0.01(0.01)$ & -0.53 & $-0.04-0.02$ \\
\hline Age & $-0.002(0.001)$ & -1.29 & $-0.01-0.001$ & $0.00(0.001)$ & 0.41 & $-0.001-0.002$ & $0.001(0.001)$ & 1.18 & $-0.001-0.003$ \\
\hline Education & $0.001(0.002)$ & 0.42 & $-0.003-0.01$ & $0.05(0.02)^{* *}$ & 3.07 & $0.02-0.08$ & $0.01(0.01)$ & 1.00 & $-0.01-0.04$ \\
\hline Gender & $0.00(0.004)$ & -0.11 & $-0.01-0.01$ & $0.03(0.03)$ & 0.84 & $-0.04-0.09$ & $-0.01(0.03)$ & -0.34 & $-0.06-0.04$ \\
\hline \multicolumn{10}{|l|}{ Correlations } \\
\hline Intercept Slope & $-0.41(0.18)$ & -2.29 & $-0.76--0.06$ & $-0.27(0.24)$ & -1.14 & $-0.73-0.19$ & $0.27(0.32)$ & 0.90 & $-0.30-0.87$ \\
\hline \multicolumn{10}{|l|}{ Model Fit Indices } \\
\hline Comparative Fit Index & & 0.946 & & - & 0.975 & & - & 0.937 & \\
\hline Robust Tucker-Lewis Ir & & 0.853 & & - & 0.934 & & - & 0.890 & \\
\hline Root Mean Square Erro & oximation (RMSEA) & 0.066 & & - & 0.050 & & - & 0.072 & \\
\hline
\end{tabular}




\section{Memory of the UK's 2016 EU Referendum: The effects of valence on the long- term measures of a public event.}

S Table 3

Predictive Factors as Mediators Between Residency and Voting Choice in (A) Memory Consistency, (B) Memory Confidence and (C) Memory Vividness After Controlling for Age, Education and Gender.

\begin{tabular}{|c|c|c|c|c|c|c|c|c|c|}
\hline & \multicolumn{3}{|c|}{ A. Memory Consistency } & \multicolumn{3}{|c|}{ B. Memory Confidence } & \multicolumn{3}{|c|}{ C. Memory Vividness } \\
\hline & $b$ (SE) & t-value & $95 \% \mathrm{CI}$ & $b$ (SE) & t-value & $95 \% \mathrm{CI}$ & $b$ (SE) & $\mathrm{t}$-value & $95 \% \mathrm{CI}$ \\
\hline \multicolumn{10}{|l|}{ Importance predicted by: } \\
\hline US vs UK & $-0.74(0.04)^{* * * *}$ & -17.34 & $-0.82--0.65$ & $-0.73(0.04)^{* * * *}$ & -17.66 & $-0.81--0.65$ & $-0.73(0.04)^{* * * *}$ & -17.69 & $-0.82--0.65$ \\
\hline Remain vs Leave & $0.22(0.07)^{* * * *}$ & 3.25 & $0.09-0.35$ & $0.22(0.07)^{* * * *}$ & 3.29 & $0.09-0.35$ & $0.20(0.07) * *$ & 3.08 & $0.07-0.33$ \\
\hline Age & $0.08(0.04)^{*}$ & 2.36 & $0.01-0.15$ & $0.01(0.003)^{*}$ & 2.33 & $0.001-0.02$ & $0.01(0.04)^{*}$ & 2.37 & $0.01-0.15$ \\
\hline Education & $0.16(0.06)^{* * *}$ & 2.89 & $0.05-0.27$ & $0.16(0.06)^{* * *}$ & 2.84 & $0.05-0.26$ & $0.16(0.06)^{* * *}$ & 2.88 & $0.05-0.27$ \\
\hline Gender & $0.07(0.11)$ & 0.65 & $-0.15-0.30$ & $0.08(0.11)$ & 0.66 & $-0.15-0.30$ & $0.08(0.11)$ & 0.66 & $-0.15-0.30$ \\
\hline \multicolumn{10}{|l|}{ Negative emotion predicted by: } \\
\hline US vs UK & $-0.36(0.04) * * *$ & -8.18 & $-0.45--0.27$ & $-0.36(0.04) * * *$ & -8.24 & $-0.45--0.27$ & $-0.36(0.04)^{* * *}$ & -8.20 & $-0.45--0.27$ \\
\hline Remain vs Leave & $1.37(0.08)^{* * * *}$ & 17.28 & $1.22-1.53$ & $1.37(0.08)^{* * * *}$ & 17.24 & $1.21-1.52$ & $1.36(0.08)^{* * * *}$ & 17.06 & $1.21-1.52$ \\
\hline Age & $-0.08(0.04) *$ & -2.03 & $-0.15--0.003$ & $-0.01(0.004)^{*}$ & -2.05 & $-0.02-0.00$ & $-0.01(0.04)^{*}$ & -2.03 & $-0.15--0.003$ \\
\hline Education & $0.18(0.06)^{* * *}$ & 2.93 & $0.06-0.31$ & $0.18(0.06)^{* * *}$ & 2.92 & $0.06-0.31$ & $0.18(0.06)^{* * *}$ & 2.92 & $0.06-0.31$ \\
\hline Gender & $0.35(0.13)^{* * *}$ & 2.78 & $0.10-0.60$ & $0.35(0.13) * *$ & 2.79 & $0.10-0.60$ & $0.35(0.13)^{\text {*** }}$ & 2.79 & $0.11-0.60$ \\
\hline \multicolumn{10}{|l|}{ Positive emotion predicted by: } \\
\hline US vs UK & $-0.30(0.05)^{* * *}$ & -6.29 & $-0.40--0.21$ & $-0.30(0.05)^{* * * *}$ & -6.37 & $-0.39--0.21$ & $-0.30(0.05) * * *$ & -6.36 & $-0.40--0.21$ \\
\hline Remain vs Leave & $-1.67(0.09)^{* * *}$ & -19.19 & $-1.85--1.50$ & $-1.68(0.09)^{* * *}$ & -19.50 & $-1.85--1.51$ & $-1.69(0.09)^{* * * *}$ & -19.52 & $-1.86--1.52$ \\
\hline Age & $0.13(0.04)^{* * *}$ & 3.01 & $0.04-0.21$ & $0.01(0.004)^{* * *}$ & 2.99 & $0.004-0.02$ & $0.01(0.04)^{* * *}$ & 3.02 & $0.04-0.21$ \\
\hline Education & $-0.12(0.06)^{*}$ & -1.95 & $-0.23-0.00$ & $-0.12(0.06)^{*}$ & -1.98 & $-0.23--0.001$ & $-0.12(0.06)^{*}$ & -1.95 & $-0.23-0.001$ \\
\hline Gender & $-0.18(0.13)$ & -1.41 & $-0.43-0.07$ & $-0.18(0.13)$ & -1.40 & $-0.43-0.07$ & $-0.18(0.13)$ & -1.40 & $-0.43-0.07$ \\
\hline \multicolumn{10}{|l|}{ Rehearsal predicted by: } \\
\hline US vs UK & $-0.42(0.03) * * *$ & -13.68 & $-0.48--0.36$ & $-0.42(0.03) * * *$ & -13.88 & $-0.47--0.36$ & $-0.42(0.03)^{* * * *}$ & -14.13 & $-0.48--0.36$ \\
\hline Remain vs Leave & $0.27(0.06)^{* * * * *}$ & 4.66 & $0.16-0.39$ & $0.27(0.06)^{* * * *}$ & 4.68 & $0.16-0.38$ & $0.26(0.06)^{* * * *}$ & 4.43 & $0.14-0.37$ \\
\hline Age & $0.05(0.03)$ & 1.83 & $-0.004-0.11$ & $0.01(0.003)$ & 1.79 & $0.00-0.01$ & $0.01(0.03)$ & 1.84 & $-0.003-0.11$ \\
\hline Education & $0.19(0.04)^{* * * *}$ & 4.60 & $0.11-0.27$ & $0.19(0.04)^{\text {***** }}$ & 4.56 & $0.11-0.27$ & $0.19(0.04)^{* * * *}$ & 4.66 & $0.11-0.27$ \\
\hline Gender & $-0.11(0.09)$ & -1.28 & $-0.28-0.06$ & $-0.11(0.09)$ & -1.29 & $-0.28-0.06$ & $-0.11(0.09)$ & -1.27 & $-0.27-0.06$ \\
\hline \multicolumn{10}{|l|}{ Surprise predicted by: } \\
\hline US vs UK & $-0.12(0.05) *$ & -2.19 & $-0.23--0.01$ & $-0.12(0.05)^{*}$ & -2.18 & $-0.22--0.01$ & $-0.12(0.05)^{*}$ & -2.20 & $-0.22--0.01$ \\
\hline Remain vs Leave & $-0.09(0.10)$ & -0.86 & $-0.29-0.11$ & $-0.09(0.10)$ & -0.87 & $-0.29-0.11$ & $-0.10(0.10)$ & -0.96 & $-0.30-0.10$ \\
\hline Age & $0.11(0.05)^{*}$ & 2.09 & $0.01-0.20$ & $0.01(0.01)^{*}$ & 2.07 & $0.001-0.02$ & $0.01(0.01)^{*}$ & 2.09 & $0.01-0.20$ \\
\hline Education & $-0.08(0.08)$ & -1.06 & $-0.23-0.07$ & $-0.08(0.08)$ & -1.09 & $-0.23-0.07$ & $-0.08(0.08)$ & -1.07 & $-0.23-0.07$ \\
\hline Gender & $0.11(0.16)$ & 0.72 & $-0.19-0.42$ & $0.11(0.16)$ & 0.73 & $-0.19-0.42$ & $0.11(0.16)$ & 0.73 & $-0.19-0.42$ \\
\hline \multicolumn{10}{|l|}{ Intercept predicted by: } \\
\hline Importance & $0.01(0.01)$ & 0.96 & $-0.01-0.03$ & $0.25(0.06)^{* * * *}$ & 3.89 & $0.12-0.38$ & $0.20(0.06)^{* * * *}$ & 3.60 & $0.09-0.30$ \\
\hline Positive Emotion & $-0.02(0.01) *$ & -2.31 & $-0.04--0.003$ & $0.04(0.05)$ & 0.86 & $-0.06-0.15$ & $0.09(0.04)^{*}$ & 2.11 & $0.01-0.16$ \\
\hline Negative Emotion & $0.002(0.01)$ & 0.23 & $-0.01-0.02$ & $-0.03(0.06)$ & -0.60 & $-0.14-0.08$ & $0.05(0.04)$ & 1.31 & $-0.03-0.13$ \\
\hline Rehearsal & $-0.01(0.01)$ & -0.74 & $-0.03-0.01$ & $0.29(0.08)^{* * * *}$ & 3.67 & $0.14-0.45$ & $0.37(0.05)^{* * * * *}$ & 7.53 & $0.28-0.47$ \\
\hline Surprise & $0.001(0.01)$ & 0.10 & $-0.01-0.01$ & $0.04(0.04)$ & 1.11 & $-0.03-0.11$ & $0.05(0.03)$ & 1.90 & $-0.001-0.10$ \\
\hline Age & $0.003(0.01)$ & 0.52 & $-0.01-0.02$ & $0.003(0.004)$ & 0.81 & $-0.01-0.01$ & $-0.003(0.003)$ & -0.92 & $-0.08-0.03$ \\
\hline Gender & $0.02(0.02)$ & 1.02 & $-0.02-0.06$ & $-0.05(0.14)$ & -0.35 & $-0.32-0.23$ & $-0.05(0.09)$ & -0.53 & $-0.23-0.13$ \\
\hline Education & $0.01(0.01)$ & 0.56 & $-0.02-0.03$ & $-0.10(0.07)$ & -1.56 & $-0.23-0.03$ & $-0.02(0.05)$ & -0.33 & $-0.12-0.08$ \\
\hline US vs UK & $-0.05(0.01) * * *$ & -4.86 & $-0.07--0.03$ & $-0.17(0.06)^{* *}$ & -2.58 & $-0.29--0.04$ & $-0.15(0.05)^{* *}$ & -3.01 & $-0.24--0.05$ \\
\hline Remain vs Leave & $-0.03(0.02)$ & -1.44 & $-0.07-0.01$ & $0.13(0.12)$ & 1.10 & $-0.10-0.36$ & $0.01(0.09)$ & 0.10 & $-0.16-0.18$ \\
\hline \multicolumn{10}{|l|}{ Slope predicted by: } \\
\hline Importance & $-0.004(0.002)$ & -1.81 & $-0.01-0.00$ & $-0.03(0.02)$ & -1.61 & $-0.06-0.01$ & $-0.03(0.01)^{*}$ & -2.30 & $-0.05--0.004$ \\
\hline Positive Emotion & $0.001(0.002)$ & 0.78 & $-0.002-0.004$ & $0.02(0.01)$ & 1.27 & $-0.01-0.04$ & $0.01(0.01)$ & 0.90 & $-0.01-0.03$ \\
\hline Negative Emotion & $-0.003(0.002)$ & -1.45 & $-0.01-0.001$ & $0.02(0.01)$ & 1.07 & $-0.01-0.04$ & $0.00(0.01)$ & -0.01 & $-0.02-0.02$ \\
\hline Rehearsal & $0.01(0.002)^{*}$ & 2.19 & $0.001-0.01$ & $-0.03(0.02)$ & -1.25 & $-0.07-0.02$ & $0.004(0.01)$ & 0.27 & $-0.02-0.03$ \\
\hline Surprise & $0.00(0.001)$ & 0.26 & $-0.002-0.003$ & $-0.004(0.01)$ & -0.43 & $-0.02-0.02$ & $-0.004(0.01)$ & -0.52 & $-0.02-0.01$ \\
\hline Age & $-0.002(0.001)$ & -1.45 & $-0.01-0.001$ & $0.001(0.001)$ & 0.60 & $-0.001-0.002$ & $0.001(0.001)$ & 1.20 & $-0.01-0.03$ \\
\hline Gender & $0.001(0.004)$ & 0.32 & $-0.01-0.01$ & $0.02(0.03)$ & 0.68 & $-0.04-0.09$ & $-0.01(0.03)$ & -0.23 & $-0.06-0.05$ \\
\hline Education & $0.001(0.002)$ & 0.64 & $-0.003-0.01$ & $0.05(0.02)^{* * * *}$ & 3.39 & $0.02-0.08$ & $0.02(0.01)$ & 1.33 & $-0.01-0.05$ \\
\hline US vs UK & $0.002(0.002)$ & 0.89 & $-0.002-0.01$ & $-0.01(0.01)$ & -0.98 & $-0.04-0.01$ & $-0.05(0.01)^{* * * *}$ & -4.34 & $-0.07--0.03$ \\
\hline Remain vs Leave & $0.01(0.004)^{* * *}$ & 2.57 & $0.002-0.02$ & $-0.03(0.03)$ & -1.13 & $-0.09-0.02$ & $0.01(0.02)$ & 0.64 & $-0.03-0.06$ \\
\hline \multicolumn{10}{|l|}{ Model Fit Indices } \\
\hline Comparative Fit Index (CFI) & & 0.986 & & - & 0.991 & & - & 0.973 & \\
\hline Robust Tucker-Lewis Index (TLI) & & 0.932 & & - & 0.955 & & - & 0.974 & \\
\hline Root Mean Square Error of Approxi & ation (RMSEA) & 0.059 & & - & 0.042 & & - & 0.058 & \\
\hline
\end{tabular}

$* p<.05 . \quad * * p<.01 . * * * \mathrm{p}<.001$ 
Memory of the UK's 2016 EU Referendum: The effects of valence on the longterm measures of a public event.

S Table 4

Growth Curve Model (SEM) for Recoded Memory Consistency

\begin{tabular}{llcc}
\hline & \multicolumn{1}{c}{$\mathrm{b}(\mathrm{SE})$} & $\mathrm{t}$-value & $95 \% \mathrm{CI}$ \\
\hline Intercept & $0.70(0.01)^{* * *}$ & 74.07 & $3.30-4.80$ \\
US vs UK & $-0.04(0.01)^{* * *}$ & -6.38 & $-0.48--0.26$ \\
Remain vs Leave & $0.01(0.01)$ & 1.15 & $-0.04-0.16$ \\
Slope & $-0.003(0.002)$ & -1.40 & $-0.27-0.05$ \\
US vs UK & $0.003(0.002)$ & 1.66 & $0.03-0.32$ \\
Remain vs Leave & $0.01(0.002)^{* *}$ & 2.61 & $0.03-0.35$
\end{tabular}

\section{Correlations}

\begin{tabular}{|c|c|c|}
\hline $\begin{array}{l}\text { Intercept Slope } \\
\text { Model Fit Indices }\end{array}$ & -4.07 & $-0.73--0.25$ \\
\hline Comparative Fit Index (CFI) & 0.997 & \\
\hline Robust Tucker-Lewis Index (TLI) & 0.991 & \\
\hline Root Mean Square Error of Approximation (RMSEA) & 0.024 & \\
\hline
\end{tabular}

$* p<.05 . \quad * * p<.01 . \quad * * * p<.001$.

S Table 5

Emotional Memory Questions that are relevant to the current analyses

\section{Emotional memory}

1) How strongly did you feel the following emotions when you found out the results? (1. Not at all to 7. Very strongly)
a. Angry
b. Surprise
c. Sad
d. Happy
e. Anxious
f. Proud 
S Table 6

Memory of Negative Emotion and Memory of Surprise as a Function of Voting Group and

Residency, Across All Surveys

Remain Leave US

\begin{tabular}{lcccccc} 
Memory assessments and survey & $M(\mathrm{SD})$ & $n$ & $M(\mathrm{SD})$ & $n$ & $M(\mathrm{SD})$ & $n$ \\
\hline Memory for Negative Emotion & & & & & & \\
$\quad$ Survey 1 & $5.61(1.23)$ & 190 & $2.05(1.15)$ & 153 & $2.80(1.58)$ & 217 \\
Survey 2 & $5.58(1.18)$ & 226 & $1.93(1.09)$ & 214 & $2.63(1.48)$ & 238 \\
Survey 3 & $5.57(1.25)$ & 222 & $1.92(1.1)$ & 212 & $2.72(1.64)$ & 228 \\
Survey 4 & $5.43(1.3)$ & 176 & $1.85(0.96)$ & 174 & $2.59(1.59)$ & 163 \\
\hline Memory for Positive Emotion & & & & & & \\
Survey 1 & $1.18(0.59)$ & 190 & $5.14(1.76)$ & 153 & $2.26(1.69)$ & 217 \\
Survey 2 & $1.29(0.66)$ & 226 & $5.31(1.69)$ & 214 & $2.10(1.55)$ & 238 \\
Survey 3 & $1.31(0.69)$ & 222 & $5.51(1.63)$ & 212 & $2.12(1.61)$ & 228 \\
Survey 4 & $1.28(0.62)$ & 176 & $5.38(1.56)$ & 174 & $2.02(1.60)$ & 163 \\
\hline Memory for Surprise & & & & & & \\
$\quad$ Survey 1 & $5.57(1.57)$ & 190 & $5.33(1.7)$ & 153 & $5.35(1.52)$ & 217 \\
Survey 2 & $5.78(1.39)$ & 226 & $5.23(1.83)$ & 214 & $5.20(1.65)$ & 238 \\
Survey 3 & $5.65(1.44)$ & 222 & $5.29(1.64)$ & 212 & $5.12(1.76)$ & 228 \\
Survey 4 & $5.68(1.38)$ & 176 & $5.31(1.63)$ & 174 & $4.98(1.84)$ & 163 \\
\hline
\end{tabular}


Memory of the UK's 2016 EU Referendum: The effects of valence on the long-term measures of a public event.

S Table 7

Growth Curve Models of (A) Memory of Negative Emotion and (B) Memory of Surprise

\begin{tabular}{|c|c|c|c|c|c|c|c|c|c|}
\hline & \multicolumn{3}{|c|}{ A. Memory of Negative Emotion } & \multicolumn{3}{|c|}{ B. Memory of Positive Emotion } & \multicolumn{3}{|c|}{ C. Memory of Surprise } \\
\hline & $\mathrm{b}(\mathrm{SE})$ & $\mathrm{t}$-value & $95 \% \mathrm{CI}$ & $\mathrm{b}(\mathrm{SE})$ & $\mathrm{t}$-value & $95 \% \mathrm{CI}$ & $\mathrm{b}(\mathrm{SE})$ & $\mathrm{t}$-value & $95 \% \mathrm{CI}$ \\
\hline Intercept & $1.25(0.09)^{* * *}$ & 77.55 & $3.35-3.53$ & $2.92(0.05)^{* * * *}$ & 60.84 & $2.83-3.02$ & $5.43(0.06)^{* * *}$ & 97.60 & $5.32-5.54$ \\
\hline US vs UK & $-0.34(0.03)^{* * *}$ & -9.96 & $-0.41--0.27$ & $-0.38(0.04)^{* * *}$ & -10.75 & $-0.46--0.31$ & $-0.07(0.04)$ & -1.71 & $-0.14-0.01$ \\
\hline Remain vs Leave & $1.84(0.05)^{* * *}$ & 37.61 & $1.74-1.93$ & $-2.04(0.06)^{* * *}$ & -37.01 & $-2.15--1.93$ & $0.21(0.07)^{* *}$ & 2.97 & $0.07-0.34$ \\
\hline Slope & $-0.02(0.01)^{*}$ & -2.13 & $-0.03--0.001$ & $-0.01(0.01)$ & -0.90 & $-0.02-0.01$ & $-0.03(0.01)^{* *}$ & -2.71 & $-0.05--0.01$ \\
\hline US vs UK & $-0.01(0.01)$ & -1.16 & $-0.02-0.01$ & $-0.003(0.01)$ & -0.56 & $-0.01-0.01$ & $-0.02(0.01)^{*}$ & -2.51 & $-0.03--0.004$ \\
\hline Remain vs Leave & $-0.01(0.01)$ & -1.37 & $-0.03-0.004$ & $0.004(0.01)$ & 0.50 & $-0.01-0.02$ & $-0.002(0.01)$ & -0.16 & $-0.02-0.02$ \\
\hline \multicolumn{10}{|l|}{ Correlation } \\
\hline Intercept Slope & $-0.14(0.10)$ & -1.50 & $-0.33-0.04$ & $-0.17-0.13$ & -1.28 & $-0.43-0.09$ & $-.04(0.13)$ & 0.76 & $-0.29-0.22$ \\
\hline \multicolumn{10}{|l|}{ Model Fit Indices } \\
\hline Comparative Fit Index (CFI) & - & 0.998 & & - & 0.999 & & - & 0.982 & \\
\hline Robust Tucker-Lewis Index (TLI) & - & 0.998 & & - & 0.999 & & - & 0.978 & \\
\hline Root Mean Square Error of Approximation (RMSEA) & - & 0.023 & & - & 0.017 & & - & 0.044 & \\
\hline
\end{tabular}

Root Mean Square Error of Approximation (RMSEA)

0.017

$* p<.05 . \quad * * \mathrm{p}<.01 . \quad * * * \mathrm{p}<.001$ 


\section{Memory of the UK's 2016 EU Referendum: The effects of valence on the long- term measures of a public event.}

\section{References}

Hirst, W., Phelps, E. A., Buckner, R. L., Budson, A. E., Cuc, A., Gabrieli, J. D. E., Johnson, M. K., Lustig, C., Lyle, K. B., Mather, M., Meksin, R., Mitchell, K. J., Ochsner, K. N., Schacter, D. L., Simons, J. S., \& Vaidya, C. J. (2009). Long-Term Memory for the Terrorist Attack of September 11: Flashbulb Memories, Event Memories, and the Factors That Influence Their Retention. Journal of Experimental Psychology: General, 138(2), 161-176. https://doi.org/10.1037/a0015527

Hirst, W., Phelps, E. A., Meksin, R., Vaidya, C. J., Johnson, M. K., Mitchell, K. J., Buckner, R. L., Budson, A. E., Gabrieli, J. D. E., Lustig, C., Mather, M., Ochsner, K. N., Schacter, D., Simons, J. S., Lyle, K. B., Cuc, A. F., \& Olsson, A. (2015). A ten-year follow-up of a study of memory for the attack of september 11, 2001: Flashbulb memories and memories for flashbulb events. Journal of Experimental Psychology: General, 144(3), 604-623. https://doi.org/10.1037/xge0000055

Levine, L. J., Prohaska, V., Burgess, S. L., Rice, J. A., \& Laulhere, T. M. (2001). Remembering past emotions: The role of current appraisals. Cognition and Emotion, 15(4), 393-417. https://doi.org/10.1080/02699930125955

Levine, L. J., \& Safer, M. (2002). Sources of bias in memory for emotions. Current Directions in Psychological Science, 11(5), 169-173. https://doi.org/10.1111/14678721.00193

Levine, L. J., Whalen, C. K., Henker, B., \& Jamner, L. D. (2005). Looking back on September 11, 2001: Appraised impact and memory for emotions in adolescents and adults. Journal of Adolescent Research, 20(4), 497-523. https://doi.org/10.1177/0743558405274893

Safer, M. A., Levine, L., \& Drapalski, A. L. (2002). Distortion in memory for emotions: The 
Memory of the UK's 2016 EU Referendum: The effects of valence on the longterm measures of a public event.

contributions of personality and post-event knowledge. Personality and Social

Psychology Bulletin, 28(11), 1495-1507. https://doi.org/10.1177/014616702237577 